\section{UCDNN}

LIBRARY
University of Connecticut OpenCommons@UConn

5-7-2015

\title{
Correlates of Recovery from Substance Use Disorders
}

William Charles Gilbert

University of Connecticut - Storrs, wcgilbert66@gmail.com

Follow this and additional works at: https://opencommons.uconn.edu/dissertations

\section{Recommended Citation}

Gilbert, William Charles, "Correlates of Recovery from Substance Use Disorders" (2015). Doctoral Dissertations. 757.

https://opencommons.uconn.edu/dissertations/757 
Correlates of Recovery from Substance Use Disorders

William Charles Gilbert, Ph.D.

University of Connecticut, 2015

This retrospective study examined the factors affecting recovery from alcohol dependence and drug dependence. A convenience sample of 263 respondents with varying lengths of recovery from a national recovery community organization and a Connecticut-based recovery community organization completed an anonymous on-line survey. The survey, which used both closed-ended and open-ended questions, was designed to collect information on drug and alcohol use and factors that contributed to the respondents' recovery from substance dependence during the respondents' first year of recovery. Recovery capital, which has its theoretical foundations in social capital theory and ecological theory, was the primary construct investigated. For this study, recovery capital was conceptualized as affiliation with twelve step groups (e.g., Alcoholics Anonymous), social support, spirituality, and respondents' financial situation during their first year of recovery. It was hypothesized that greater levels of recovery capital are associated with higher levels of alcohol abstinence self-efficacy, and drug abstinence self-efficacy. Bandura originally conceptualized self-efficacy as those internal and external factors, which motivate a person to change behavior. Researchers operationalized this to measure the level of self-efficacy to abstain from drug, and/or alcohol use. The relationship between recovery and substance abuse treatment was also investigated. It was hypothesized that the level of self-efficacy to abstain from alcohol and drug use is moderated by completion of substance abuse treatment during the first year of recovery. Findings revealed that recovery capital is a statistically significant predictor of alcohol abstinence self-efficacy and drug abstinence selfefficacy. Findings did not support the hypothesis that treatment completion acts as a 
moderator for recovery capital and substance abstinence self-efficacy. The answers to open-ended questions also reflected the importance of 12-step affiliation, social support, and spirituality in successful recovery. The study concluded by discussing the relevance of recovery capital construct for guiding social work practice and education. Given the salience of the recovery capital domains in positively influencing ongoing substance use recovery, the researcher proposed the inclusion of spirituality and 12Step philosophy as integral components in social work treatment and social work education. 
Correlates of Recovery from Substance Use Disorders

William Charles Gilbert, MSW

MSW, Boston College, 1990

BA, Boston College, 1988

\author{
A Dissertation \\ Submitted in Partial Fulfillment of the \\ Requirements for the Degree of \\ Doctor of Philosophy \\ at \\ University of Connecticut \\ 2015
}


Copyright by

William Charles Gilbert 


\section{APPROVAL PAGE}

Doctor of Philosophy Dissertation

Correlates of Recovery from Substance Use Disorders

\section{Presented by}

William Charles Gilbert, BA, MSW

Major Advisor

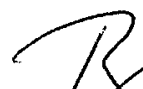

Brehda Kurz, Ph.D.

Associate Advisor

Leicla Auman Linda Frisman, Ph.D.

Associate Advisor

$2 \sim \operatorname{lon} / k$

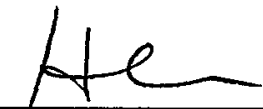

Nina Rovinelli-Heller, Ph.D.

Associate Advisor

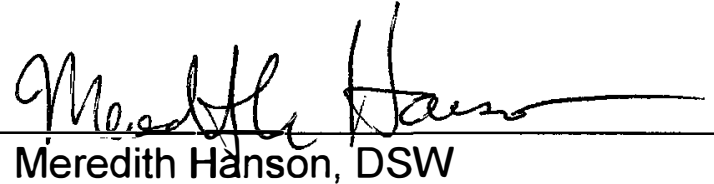

University of Connecticut 2015 


\section{Acknowledgments}

Thank you to all the recovering people who were willing to take part in this study. Your strength and perseverance is inspiring. I have learned much from all of you.

Thanks to Dr. Brenda Kurz for your constant support, encouragement, and persistence for excellence throughout this challenging and life-changing process.

Thank you to my advisors, Drs. Frisman, Rovinelli-Heller, and Hanson for the gifts of your expertise and wisdom.

Thanks, Dr. Tom Broffman for being my mentor and encouraging me to pursue my doctorate.

Thank you, Dr. Alex Gitterman for your power of example as a social worker and scholar.

Thanks mom and dad for providing me with the unconditional love that only parents as wonderful as you could provide. That love has and always will be a motivation to work hard and do well.

Thanks Lindsay, Alison, and Ryan for being the best children a father could ask for even during the times when I was buried in my work with little time to talk. Know that while my work is important, it pales in comparison to the love and pride I have for all of you.

Finally and most importantly, thanks to my wife, Patrice. I know that this has not been an easy adventure for you, but you were always there for me through those long and tiring nights. Your encouragement and cheerleading strengthened my resolve. I will never forget the sacrifices you made that allowed me to realize this dream. Love ya. 


\section{Table of Contents}

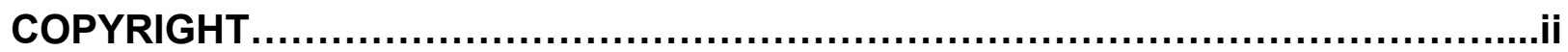

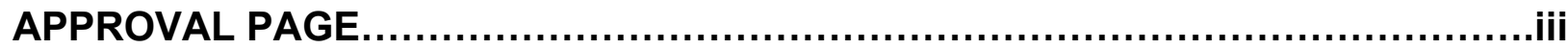

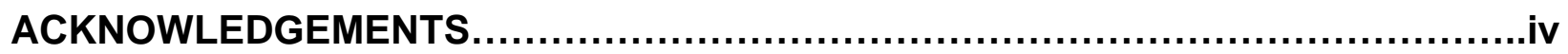

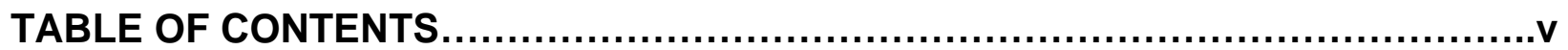

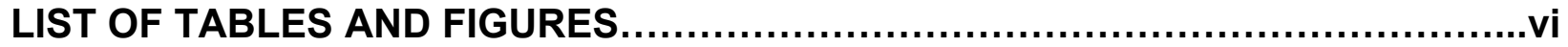

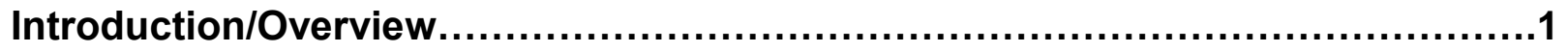

Chapter One: Literature Review............................................................

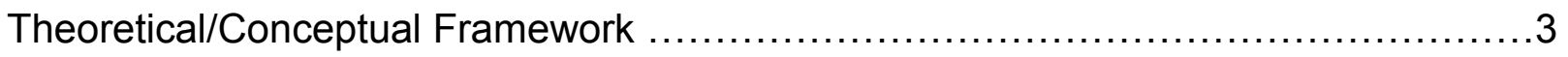

Research Questions and Related Hypotheses....................................... 31

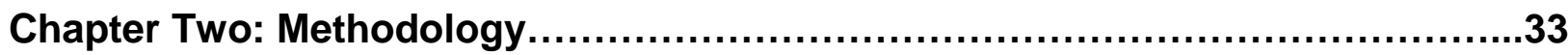

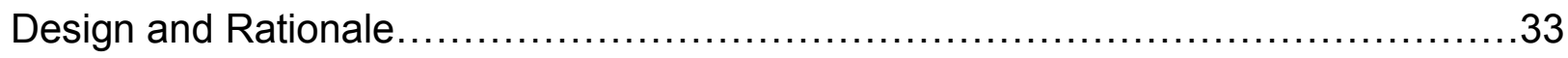

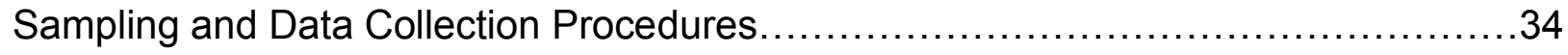

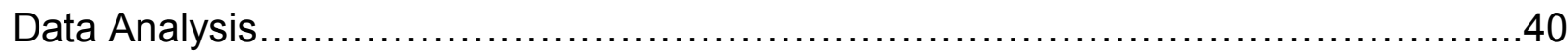

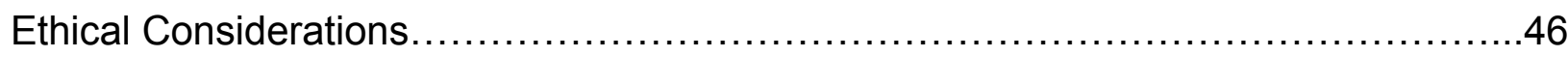

Chapter Three: Findings.......................................................................

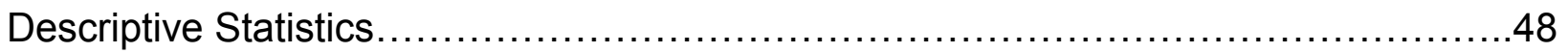

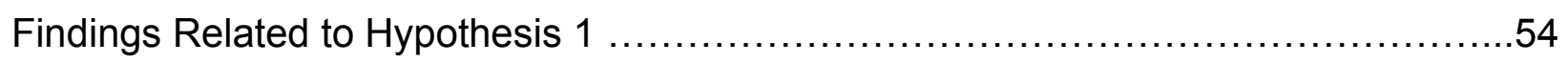

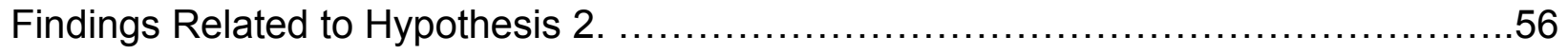

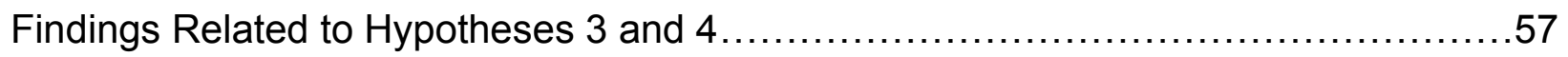

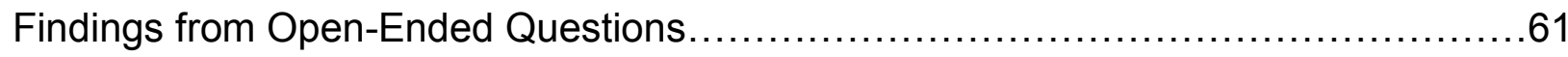

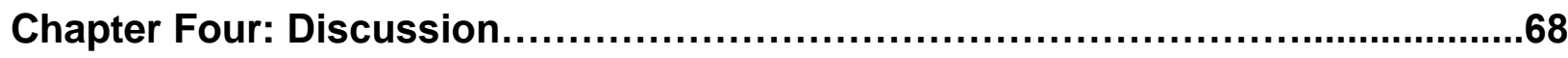

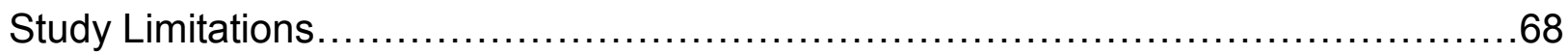

Discussions of Recovery Capital and the Domains................................... 70

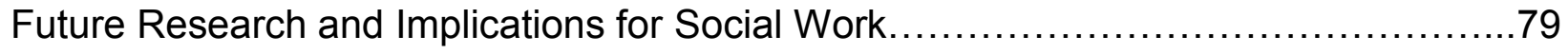

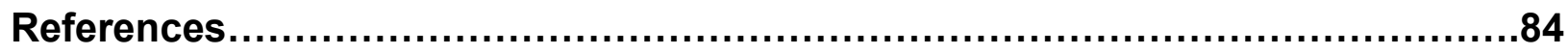

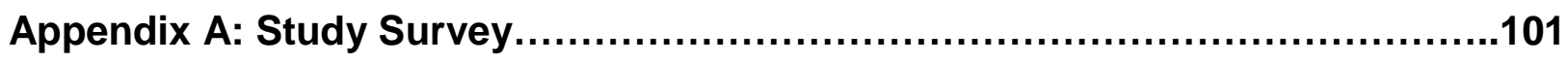


List of Tables and Figures

Tables

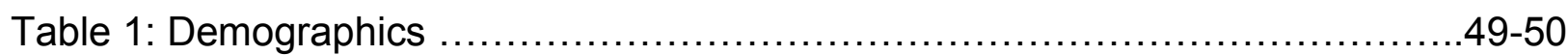

Table 2: Drug, Alcohol, Treatment Recovery-Related Descriptives ..................51-52

Table 3: Cronbach Alpha Scores for Scales …...................................... 53

Table 4: Correlations for Independent Variables for Recovery Capital....................54

Table 5: Mean scores of Recovery Capital Domains (IVs) .............................54

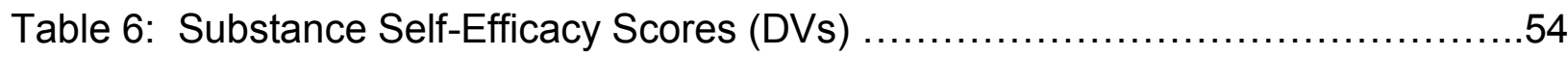

Table 7: Hierarchical Regression Analysis Summary for the Indexed Recovery Capital Model Predicting Alcohol Abstinence Efficacy and Drug Abstinence Efficacy

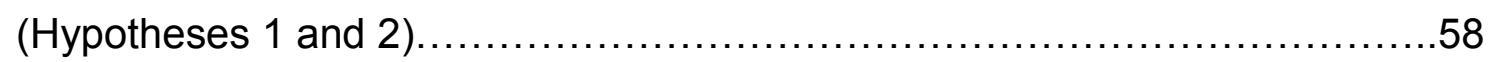

Table 8: Hierarchical Regression Analysis Summary for Recovery Capital Variables Predicting Alcohol Abstinence Efficacy and Drug Abstinence Efficacy (Hypotheses 1 and 2) .59

Table 9: Hierarchical Regression Analysis Summary for Treatment Completion as a Moderator of Recovery Capital Variables in Predicting Alcohol Abstinence Efficacy and Drug Abstinence Efficacy (Hypotheses 3 and 4).

Figures

Figure 1: Hypothesized Effect of Recovery Capital on Alcohol and Drug Abstinence Self-Efficacy .99

Figure 2: Hypothesized Moderating Effects of Treatment 100 


\section{Introduction/Overview}

Substance use disorders are pervasive in the United States. Recent statistics estimate that the number of people in the United States suffering from substance use disorders (either substance dependence or substance abuse) is 22.6 million (Ross \& Pesalow, 2009). While use of illicit drugs leads to significant health and social problems, alcohol use alone leads to catastrophic health consequences. The World Health Organization (WHO) estimated that alcohol causes 2.5 million deaths worldwide (WHO, 2004). SAMHSA (2003) data revealed that 14 million adults suffered from alcohol dependence or abuse. Findings from the National Epidemiologic Survey on Alcohol and Related Conditions revealed a lifetime prevalence of $12.5 \%$ for alcoholism and a prevalence of $3.8 \%$ over the past twelve months (Hasin, Stinson, Ogburn \& Grant, 2009). Furthermore, recent data from the United States Substance Abuse and Mental Health Services Administration (SAMHSA, 2012) revealed that drug use and drug use in combination with alcohol brought over 1.7 million people to treatment. Of those 1.7 million people studied, $26 \%$ were treated for opiate use (e.g., heroin, pain medications); $21.4 \%$ received treatment for alcohol use only; $17.5 \%$ were treated for alcohol in combination with other drugs; $7 \%$ were treated for cocaine use ;, and $28.2 \%$ were treated for all other drugs, including marijuana.

Recovery from alcohol and drug use disorders has been studied for several decades (e.g., Laudet \& White, 2008; Marlatt, 1985, 2005; McKellar, Stewart \& Humphreys, 2003; Valliant, 1983, 1995). Cloud and Granfield (1999) studied a group of people who experienced spontaneous recovery, defined as abstinence from alcohol without the assistance of treatment or Alcoholics Anonymous. Their work is particularly relevant for the current study as they developed the concept of recovery capital, a 
concept that is central to the current study. For most, however, substance abuse treatment is crucial to ongoing recovery (e.g., SAMHSA Treatment Episode Data Set, 2007). Still others found that attending Alcoholics Anonymous is an important for recovery (e.g., Connors, Tonigan \& Miller, 2001; Krentzman, 2008). Marlatt (1985) studied relapse or the return to a use of alcohol after a period of abstinence to understand factors that can disrupt recovery. Marlatt found that both internal and external risk factors could lead to relapse. Bandura $(1977,1983$ \&1989) understood the role of self-efficacy and research found it to be a salient factor in recovery. The interplay between these factors that promotes recovery and the risk factors that jeopardize abstinence and lead to relapse place the alcohol or drug dependent client on a precarious life course.

The research reviewed in this chapter will underscore the importance of those environmental factors that influence recovery. Because social work operates from an ecological perspective, the study and understanding of these factors is exceedingly relevant to the profession. This chapter concludes with a discussion of an innovative construct for recovery, recovery capital, which has significant implications for social work practice.

\section{Statement of the Problem}

Recovery from alcohol and drug dependence is a process that involves many environmental, interpersonal, and intrapersonal factors, referred to as recovery capital that promote and inhibit recovery. Understanding which domains of recovery capital promote recovery is critical in helping clients sustain recovery. 


\section{Chapter One: Literature Review}

\section{Recovery Capital, Alcohol and Drug Dependence, Recovery and Relapse Recovery Capital}

Recovery capital, a major concept for the present study, is defined by Cloud and Granfield (1999) as those "critical elements that an individual possesses or that exist within his or her immediate surroundings and that function to promote a sustained recovery experience" (p. 179). These critical elements include social capital defined as social support from friends and relatives, human capital defined as intrinsic qualities that a person possesses such as knowledge, skills, physical health and mental health, and physical capital defined "as economic or financial capital, [which] included income, savings, property, investments, and other tangible financial assets that can be converted to money" (Cloud \& Granfield, 2008, p.44). This literature review will describe the century long process of developing this understanding of recovery capital. First, however, alcohol and drug dependence, recovery, and relapse and the related concept of self-efficacy are defined and discussed briefly.

\section{Alcohol and Drug Dependence}

Our understanding of substance dependence and recovery began soon after the American Revolution, when physicians and the public recognized the significant problems that alcohol use could cause. White (1998) described the groundbreaking work of physician Benjamin Rush (1746-1813) who was one of the first American physicians (and the only physician to sign the Declaration of Independence) (Cloud \& Granfield, 1999) to address the growing problem of alcohol use in the fledgling country. 
Rush also introduced the concept that alcoholism is a disease and acknowledged that defining it as such would be controversial: "I am aware that the efforts of science and humanity, in applying their resources to the cure of a disease induced by a vice will meet with a cold reception" (as cited by White, 1998, p.2).

Since the days of Rush, scientists have adopted the concept of alcohol and drug dependence as a disease (Jellinek, 1960). The American Psychiatric Association assumed this disease model and used criteria developed from research on the alcohol dependence syndrome (Edwards \& Gross, 1976). The APA defines a progression from alcohol or drug abuse that can lead to the development of alcohol or drug dependence. The APA's Diagnostic and Statistical Manual (DSM) IV-Text Revision (APA, 2000) uses the term substance to refer alcohol and/or drugs and defines substance abuse as:

... a pattern of substance use leading to clinically significant impairment or distress, as manifested by one (or more) of the following occurring within a 12 month period: (1) recurrent use resulting in a failure to fulfill major obligations at work, school, or home. . ; (2) recurrent use in situations in which it is physically hazardous . . .; (3) recurrent substance-related legal problems; (4) continued use despite having persistent or recurrent social or interpersonal problems caused by or exacerbated by the effects of the substance. (p. 199).

Substance dependence differs in that there is more significant deficit caused by the use of substances that leads to physiological and psychological symptoms including tolerance, withdrawal, use of a substance in greater quantities or for a longer period than anticipated, and the inability to cease use (loss of control). The DSM defined substance dependence as "A maladaptive pattern of substance use, leading to clinically 
significant impairment or distress" (APA, 2000, p.197). The DSM-IV definition is used because of its common use and acceptance in behavioral health treatment. The newly published DSM-5 (APA, 2014) has replaced the diagnostic criteria of substance abuse and substance dependence with "substance use disorder" with mild, moderate, and severe modifiers. However, since the publications discussed in this chapter refer to the DSM-IV or earlier editions, and use of revised diagnostic criteria are not required for professional use until October 1, 2015 (NASW, 2014), the DSM 5 criteria and language will not be used to maintain consistency throughout. For the purposes of the present study, this disease model of alcohol dependence will be used as the framework for recovery.

\section{Recovery}

With the unhealthy use of a substance being viewed as the cause of the disease, logic dictated that the only means to recover is complete abstinence from any moodaltering substance. As early as 1814 , Rush advocated for complete abstinence from alcohol as a means to recovery (White, 1998).

'Taste not, handle not,' should be inscribed upon every vessel that contains the spirits in the house of a man, who wishes to be cured of habits of temperance (White, 1998, p. 3).

As already noted, Rush understood the controversy he caused by claiming that alcoholism is a disease. In response to this controversy, he advocated for various types of treatment, which now would be considered archaic (e.g. bloodletting and blistering the skin). In addition to these traditional (for the time) treatments for disease, persons suffering from alcohol dependence would "take the pledge," agreeing never to use 
alcohol again (White, 1998). Thus, even during the infancy of this country, the complete abstinence from alcohol was deemed crucial to recovery. While programs exist today that allow for a reduction in alcohol consumption for those diagnosed as substance dependent (i.e., harm reduction models of recovery), ultimately the goal for most is complete abstinence from alcohol use (Mancini, Linhorst, Broderick \& Bayliff, 2008). For this reason and due to historical precedence, recovery for the present study will be defined as complete abstinence from substances.

\section{Relapse}

Central to maintaining recovery from substance dependence is preventing relapse. Several definitions of relapse have appeared in the substance abuse literature over the past few decades (Rahill, Lopez, Vanderbiest \& Rice, 2009). Larimer, Palmer, and Marlatt (1999) viewed relapse as a process that includes the exposure to risk factors leading to the return to alcohol use. This research study viewed relapse as a process that leads to a "return to a disease state following a period of remission" (Rahill, et al., 2009, p. 246). Such a definition is consistent with the recovery model of complete abstinence from substances.

The primary risk factors (Marlatt, 1985; 2005) associated with this relapse process include "negative emotional states such as anger, anxiety, depression, frustration and boredom . . social pressure ... [or] positive emotional states ... [and] exposure to alcohol related stimuli or cues" (Larimer, Palmer, \& Marlatt, 1999, p. 153). In a replication study of Marlatt's relapse taxonomy, the two risk factors found to predict relapse were negative emotional states and social pressure; positive emotions predicted 
relapses that resulted in lighter drinking than negative emotions such as depression and anxiety (Lowman \& Allen, 1996).

\section{Self-efficacy theory and relapse}

Self-efficacy theory has also been applied to help understand and predict relapse. This theory was first promoted by Bandura $(1977,1983$ \&1989) and later used to understand relapse (Marlatt \& Gordon, 1985). Bandura described self-efficacy as a learning process where one gains mastery over desired outcomes:

Self-motivation involves standards against which to evaluate performance. By making self-rewarding reactions conditional on attaining certain level of behavior, individuals create self-inducements to persist in their efforts until their performances match self-perceived standards (Bandura, 1977, p.193).

Here Bandura is setting the foundation for his self-efficacy theory by highlighting the importance of self-motivation in determining behavior. Self-motivation is a key to understanding the behavior of relapse.

Bandura postulated that there are four dimensions of efficacy expectations: performance accomplishments, vicarious experience, verbal persuasion, and emotional arousal. Performance accomplishments relate to those activities in which a person has realized "personal mastery experiences" (Bandura, 1977, p. 195). More success over an obstacle raises expectations that there will be future success; frequent failures to master an obstacle lower those expectations. Bandura viewed vicarious experiences as those that a person watches another person encounter. By watching another person succeed, he/she is buoyed by that success: "Seeing others perform threatening activities without adverse consequences can generate expectations in observers that 
they too will succeed" (p. 197). Bandura understood that self-efficacy is a multi-faceted construct that was determined by several factors.

Verbal persuasion, i.e., encouragement from others that one can accomplish a goal, is common, yet as Bandura noted, it is not as effective as other dimensions of selfefficacy. Bandura believed that such praise is easily discounted when a person experiences failure. Finally, emotional arousal plays a role in self-efficacy. Exposure to high stress experiences lead to fear and anxiety. That fear can build and "generate further fear of impending stressful situations through anticipatory self-arousal" (p.199). Success over these stressful episodes by using compensatory behaviors can result in increased self-efficacy.

Researchers have applied self-efficacy theory to the recovery process. Marlatt and Gordon (1985) viewed self-efficacy as a having an important role in relapse prevention. In Relapse Prevention (2005), the authors have labeled self-efficacy as one the "intrapersonal determinants" (p.8) of relapse. Similarly, Connors, Maisto and Zywiak (1996) learned that self-efficacy (confidence scores from the Situational Confidence Questionnaire, Annis, 1986) at six months after the beginning of treatment was significantly related to increased time abstinent. Likewise, in their study of 100 patients hospitalized for alcohol treatment, Greenfield, Hufford, Vagge, Muenz, Costello and Weiss (2000) determined that those patients with higher levels of self-efficacy as measured by the Situational Confidence Questionnaire had longer periods of abstinence than those with lower scores.

Following Annis's lead (1986), DiClemente, Rosario, Montgomery and Hughes (1994) developed their own scale, the Alcohol Abstinence Self-Efficacy Scale. Using self- 
efficacy theory as its foundation, the scale measures a respondent's level of selfefficacy in his/her ability to maintain abstinence. In developing the scale, factor analysis revealed four reliable subscales: negative affect $(\alpha=.88)$, social/positive and "use of alcohol to enhance emotional states" (DiClemente, et al., 1994, p. 144) ( $\alpha=.82)$, physical and other concerns $(\alpha=.83)$, and withdrawal and urges $(\alpha=.81)$. These subscales then consistently represented those situations that can lead to relapse. The authors noted that items in the "physical and other concerns" subscale are similar to the relapse triggers developed by Marlatt and Gordon $(1985,2005)$. The Alcohol Abstinence SelfEfficacy Scale was later adapted to study self-efficacy for drug abstinence (Drug Abstinence Self-Efficacy Scale).

\section{Alcoholics Anonymous and Narcotics Anonymous}

Whereas current scholars have research tools and data that allow them to understand the nuances of addiction and recovery, such was not the case when the recovery movement was in its infancy. The founders of Alcoholics Anonymous did, however, have their own experiences to contribute to the understanding of recovery. Their early work successfully laid a foundation for future researchers and clinicians to build upon. While the 12-step philosophy was developed to promote recovery from alcohol, drug recovery proponents used a similar method (as will be discussed). Thus, twelve-step recovery has become the hallmark method of recovery from addiction. This type of recovery began with Bill Wilson, who created what would become the most recognizable method of recovery, Alcoholics Anonymous (AA).

White (1998) describes the slow development of Alcoholics Anonymous, beginning in 1935. In developing the tenets of AA, Wilson integrated his personal 
journal of recovery. Throughout his struggles to maintain sobriety, Wilson sought the guidance of medical doctor William Silkworth. Silkworth, like Rush before him, viewed alcoholism as a disease and, specifically as an allergy to alcohol. While Wilson initially had difficulty accepting the idea of alcoholism as a disease, he eventually endorsed the idea. This disease model of alcoholism became an important facet of AA. Later, Wilson would team with another struggling alcoholic, Bob Smith, a physician, who would continue to advocate for the disease model of alcoholism (Kurtz, 1979).

Another important figure in the development of AA was Carl Jung. Jung, who had treated an acquaintance of Bill Smith, stressed the importance of spirituality and religion to recovery. The subsequent sobriety of his friend, who on Jung's advice sought out a spiritual experience and joined the Oxford Group, planted the seed of the importance of spirituality in recovery. Oxford Groups were popular in the 1920 s and 1930s and promoted the healing of problems through "personal spiritual change" (White, 1998, p.128). Wilson struggled with the importance of religion or spirituality as a part of recovery. Kurtz (1979) notes that Wilson had concerns about religion, "The word religion troubled him (Wilson) deeply. . . Wilson had no 'religion' beyond an adolescent romanticism. . . [and Wilson] knew that he would not tolerate being preached at" ( $p$. 16). Moreover, Wilson did not accept the importance of spirituality for maintaining sobriety until he experienced a life-changing event:

Suddenly the room lit up with a great white light. I was caught up into an ecstasy which there is $[$ sic] no words to describe ... A great peace stole over me ... (Kurtz, 1979, p.20). 
This very personal event compelled Wilson to include spirituality in the framework of Alcoholics Anonymous. Spirituality plays a key role in the effectiveness of AA and recovery in general.

Using a spiritual model for recovery, Wilson developed the Twelve Steps and later the Twelve Traditions. He understood the importance of meeting the beliefs of the religious conservatives without offending liberals. Therefore, the Twelve Steps incorporates references to "God" without endorsing a specific religion. The Twelve Steps provides a guide for recovery that is steeped in personal change and spiritual healing. In Twelve Steps and Twelve Traditions (Wilson, 1953, 1981, p. 7-9), Alcoholics Anonymous defines the twelve steps so crucial to its method of recovery:

1. We admitted we are powerless over alcohol- that our lives became unmanageable.

2. Came to believe that a Power greater than ourselves could restore us to sanity.

3. Made a decision to turn our will and our lives over to the care of God, as we understood Him.

4. Made a searching and fearless moral inventory of ourselves.

5. Admitted to God, to ourselves, and to another human being the exact nature of our wrongs.

6. Were entirely ready to have God remove all these defects of character.

7. Humbly asked to Him to remove our shortcomings.

8. Made a list of all persons we had harmed, and became willing to make amends to them all. 
9. Made direct amends to such people wherever possible, except when to do so would injure them or others.

10. Continued to take personal inventory and when we were wrong promptly admitted it.

11. Sought through prayer and meditation to improve our conscious contact with God, as we understood Him, praying only for knowledge of His will for us and the power to carry that out.

12. Having had a spiritual awakening as the result of these steps, we tried to carry this message to alcoholics and to practice these principles in all our affairs.

The Twelve Steps have proven over the years to be an important cornerstone for people in recovery from alcohol dependence and have been incorporated into many of today's treatment programs.

Similarly, Narcotics Anonymous (NA) has been shown to be effective as well. NA uses the same twelve-steps developed by AA, with one exception. Rather than a focus on alcohol, the NA steps speak of the "addiction." The word "addiction" is more general, allowing for the inclusion of different drugs (rather than just alcohol and alcoholism) while also placing the focus on the problem rather than the specific substance (Peyrot, 1985). In addition to these differences from AA, NA developed differently than AA. With its roots in the United States Public Health Service in Lexington, Kentucky and driven by a perceived need for a support network that better met the needs of drug addicts, NA prospered under the guidance of Jimmy K, a disciple of Bill W and the AA movement (Peyrot, 1985). Jimmy K. and other members of a NA 
meeting in Sun Valley, California, developed a NA fellowship that was successful, however, many people who attended NA also attended AA (Peyrot, 1985).

While definitive aggregate data on attendance at NA and AA meetings are not available (since attendance is not taken at meetings), AA remains, at least anecdotally, more widely attended than NA. AA boasts a worldwide membership of 2,138,142 members attending 115,358 distinct groups (AA General Service Office, 2014). In comparison, NA cites a total of more than 63,000 meetings worldwide (NA Membership Survey, 2014).

Abstinence rates of those attending NA/AA and those not attending NA/AA were compared in a longitudinal study by Gossop, Stewart and Marsden (2007) in Great Britain. The drug abstinence rates of recovering drug-addicted men and women by drug and treatment over a five-year period were compared. A cohort of 142 clients in residential treatment participated in structured interviews at admission, one year after discharge, two years after discharge, and then at four to five year follow-up. The focus of the study was to determine the differences between those in treatment who also attended NA/AA and those who attended the same treatment program but who did not attend NA/AA. Results revealed differences in the two groups as well as differences in the substance used. Those recovering from opiate dependence were more likely to abstain from opiate use over the five-year period. People were more likely to remain abstinent from alcohol at all the follow-up points, but overall abstinence rates were not affected by participation in NA/AA. Similarly, those in recovery from stimulant use were more likely to abstain at follow-up times, but the overall effect of NA/AA was not significant. Perhaps the most interesting result from this study was that people 
diagnosed as drug-dependent and who attended NA/AA were more likely to remain abstinent from alcohol. Thus, attendance to Narcotics Anonymous was helpful in maintaining alcohol sobriety. The authors noted that other studies (such as in an earlier study by Gossop, Brown, Stewart and Marsden, 2003) did not reveal this effect of NA on alcohol abstinence. The reasoned that such a finding should encourage programs to use NA and/or AA in treatment

\section{Effectiveness of Alcoholics Anonymous, Narcotics Anonymous and Substance}

\section{Abuse Treatment}

Over the past few decades, researchers have attempted to understand the reasons (beyond the anecdotal) for Alcoholics Anonymous' value in helping people recover from alcoholism. McKellar, Stewart, and Humphreys (2003) conducted a longitudinal study of 2,319 alcohol dependent males in treatment to determine if adding AA to their treatment affected subsequent alcohol consumption. AA involvement during the first year of recovery predicted fewer alcohol related problems in the second year. Furthermore, the findings also revealed that the effectiveness of AA was independent of previous experience with AA or serious mental illness. In contrast, the Surgeon General's 1999 Report noted that people suffering from both substance use disorders and mental disorders had better treatment outcomes from behavioral or motivational treatment than twelve-step treatment. In a 16-year longitudinal study, Moos and Moos (2006) found that attendance at AA positively related to enhanced self-efficacy.

Particularly relevant to the present discussion is research performed to determine which aspects of Alcoholics Anonymous are most beneficial to recovery. Past studies tended to focus on the number of AA meetings a person attended in determining AA's efficacy. 
Other studies explored additional aspects of Alcoholic Anonymous thought to be related to effectiveness rather than just attendance to meetings.

Tonigan, Connors, and Miller (1996) developed the Alcoholics Anonymous Involvement (AAI) Scale. The 13-item scale measures similar dimensions of AA involvement as the Alcoholics Anonymous Affiliation Scale, but includes questions on a person's compliance with following the twelve steps of Alcoholics Anonymous. A study by the authors of the measure found it to be a valid tool in measuring involvement in Alcoholics Anonymous. Their measure was used and validated with a sample that was currently in a treatment setting, precluding its applicability to alcohol dependent people not in treatment. Their findings also revealed that $49 \%$ of the variance was determined by meeting attendance and $A A$ involvement. The authors suggest that $A A$ involvement could be measured by using those two factors as subscales.

Humphreys et al. (1998) developed and validated the Alcoholics Anonymous Affiliation Scale that also measures a person's level of involvement in AA. The authors validated the nine-item scale with a sample of 927 respondents who were enrolled in treatment programs and a sample of 674 respondents who had not been in treatment for at least one year. The survey measured several dimensions of participation in AA activities, and not, as in the above measure, exclusively attendance patterns, including sponsorship, AA related activities and spirituality. Another study (Morgenstern, Lebouvie, McCrady, Kahler \& Frey, 1997) showed that AA affiliation was positively related to self-efficacy. While AA attendance is important, such studies show the salience of deeper involvement in the AA process. 
Treatment programs for substance use disorders have an important role in recovery and have been a part of the American recovery movement for centuries. The first alcohol and drug treatment programs date back to latter half of the nineteenth century with the advent of inebriate homes and asylums (White, 1998), These institutions provided help for recovering people by providing room and board in addition to treatment to cure inebriety (the term commonly used to describe alcoholism). Physicians as well as people in recovery would staff these institutions. Treatment methods included "isolation" from daily stressors, detoxification, and holistic "physical restoration" as well as religious and spiritual activities while fostering the development of social support (even then seen as an important component of recovery). Other less desirable treatment methods included "induced aversion," which used the principles of classical conditioning and overwhelmed patients with alcohol in the hope that they would no longer desire the substance:

... patients . . . were encouraged to drink all of the whiskey they wished. In fact, that is all they could drink_... whiskey-saturated coffee, whiskeysaturated tea, and whiskey saturated milk ... Patients wore whiskey-sprayed clothes and slept in whiskey-saturated sheets (White, 1998, p. 39).

While not all the treatment methods would be used in today's programs, the inebriate homes established a model for future programs.

Today's treatment programs can offer a full continuum of care from medical detoxification from alcohol and drugs and to intensive and intermediate residential treatment and finally outpatient programs. Common treatment methods used today within in these programs include relapse prevention (Marlatt, 2005), motivational 
enhancement therapy (Miller, Zweben, DiClemente \& Rychtarik, 1992) and motivational interviewing (Miller \& Rollnick, 2013). In addition to these methods, twelve-step facilitated treatment has been shown to be effective in facilitating recovery.

Beginning with the Hazelden Foundation in 1949, substance abuse treatment programs were developed, using the tenets of Alcoholics Anonymous. TSF became a popular method of treatment and continues today. TSF treatment has various iterations, from the inclusion of twelve-step meetings in the treatment program to manual-driven treatment protocols (SAMHSA, 2008). TSF was found to be an effective method of treatment for substance use disorders (Babor \& Del Boca (Eds.), 2003; Ouimette, Finney \& Moos, 1997; Sheehan, 2004). Similarly, the federally funded Project MATCH study (Babor \& Del Boca (Eds.), 2003) found that a manual -driven twelve week, twelve-session TSF therapy program, which promoted attendance to AA, was positively associated with abstinence rates. Note that instead of researching the effectiveness of AA meetings, these studies explored the use of the AA as model of recovery within a treatment facility.

Twelve-step facilitated treatment incorporates active participation of the therapist in assisting their clients' involvement in the tenets of Alcoholics Anonymous or other twelve-step fellowships. Included in this method of treatment is the understanding of alcoholism or drug addiction as a disease, and the need "'to surrender,' which involves giving oneself over to a higher power, accepting the fellowship of other recovering alcoholics, and following the recovery activities laid out by the Twelve-Step program" (Donovan, et al., 2003, p. 48). As Sheehan (2004) notes, TSF also incorporates the need for spirituality as part of the treatment process, which is important as it 
emphasizes that the recovering person understands the need for something outside of him or herself to stop drinking or using drugs. Implied in this method of treatment is that, for the most part, people cannot accomplish abstinence by sheer willpower; addiction is viewed as a disease that cannot be arrested without the help of something beyond the person:

The concept of a higher power is tied to the biological basis of addiction, which is outside the realm of voluntary control and motivates the offender to seek connections and resources beyond the limits of oneself. Spirituality provides an avenue to reconnect with personal belief systems and values allowing for strength and meaning beyond willpower (Sheehan, 2004, p.74).

The concept of a higher power, then, is key to the spiritual philosophy of a 12-step program. Such a philosophy promotes the acceptance of the illness of addiction and powerlessness often discussed in AA meetings.

Tonigan, Connors, and Miller (2003) compared the effectiveness of twelve stepfacilitated treatment (TSF), cognitive behavioral treatment and motivational enhancement treatment for a cohort of alcoholic patients in outpatient treatment. Twelve-step facilitated treatment resulted in longer abstinence. The authors hypothesized that the reason for the superiority of TSF was the "abstinence philosophy and social support aspects underlying the AA-based TSF approach" ((Babor, Steinberg, Zweben, Cisler, Stout, Tonigan, Anton \& Allen, p. 163). In another study (Ouimette, Finney \& Moos, 1997), the researchers examined the treatment outcomes of 3,699 men who were treated for alcohol dependence at the Veterans' Administration inpatient treatment programs following detox. Fifteen programs were selected from a pool of 174 
programs because of their treatment protocols: twelve-step facilitation, cognitive behavioral treatment or a combination of both protocols. Treatment effectiveness was studied twelve months following discharge from the program. Respondents who attended 12-step facilitated treatment were 1.54 times more likely to be abstinent after one year than were those who received cognitive behavioral treatment.

During the 1990's, Project Match, a federally funded (US National Institute on Alcohol Abuse and Alcoholism) study was performed to determine the best treatment methodologies for specific types of alcoholics. Overall Project Match (2003) findings revealed that alcohol dependent subjects who attended Alcoholics Anonymous had greater levels of abstinence) than those who did not attend AA. The authors note, however, that attending AA is not the only factor contributing to abstinence. Twelvestep facilitated treatment was also a key determinant in the abstinence rates.

\section{Social Capital and Social Support}

The construct of social capital helps explain how Alcoholics Anonymous is effective in helping people recover from alcoholism. Social capital was first alluded to by Durkheim, in his discussion of social integration, whereby parties engage each other in "a common social structure" to the benefit (or harm) of that social structure (as cited in Portes, 1998, p. 8-9). Later, theorists such as the sociologist Bourdieu (1986) clarified that social capital was the sum of a network of established relationships that provide "mutual acquaintance or recognition" (p. 248). Thus, a person must actively seek out and establish connections with others to establish social capital. Such is the case when a recovering alcoholic establishes connections with Alcoholics Anonymous. 
Glaeser, Laibson, and Sacerdote (2002) conceptualized social capital from an economics perspective and viewed social capital as a form of investment, albeit a personal investment. The authors stated that one way that a person may make this personal investment is through membership in a social network: "These networks could be specific organizations [sic], such as bowling leagues, or broad cases of individuals with a common social characteristic" (Glaeser, et al., 2002, p. F433). Further, this individual investment into a network can benefit the entire network. Such network membership is akin to participating in Alcoholics Anonymous: the individual makes an investment into the AA community and benefits personally from the membership (sobriety). In turn, the entire network (the AA community) benefits from the consequential additional recovery insight and support.

Several authors have operationalized social capital as social support (Best \& Laudet, 2008; Cloud \& Granfield, 2008; Granfield \& Cloud, 2001) and social support that promotes abstinence has been shown to increase the likelihood of recovery from alcoholism. For example, such social support outside of treatment was found to be lacking in a cohort of recovering substance abusing women. The authors of this study (Marcenko \& Spence, 1995) suggest that this may be the result of the respondents' alienation from their family and friends due to their drug use and/or a response to the family members' own drug use. The authors contend that providing positive social support to recovering people could facilitate treatment. Social support that promotes abstinence was also revealed as a key factor in a study of a residential substance abuse treatment program for women and their children (Wong, 2006). This mixedmethods study that used intensive interviews and observation measured family social 
support. The study revealed that the social support function of the treatment setting was an important factor in facilitating a positive treatment experience. The study also found that positive social support outside of the treatment facility was lacking and concluded that:

Individual support provided by the staff regardless of their roles and functions appears imperative in the mothers' development of a rudimentary sense of self and a healthy relationship. Thus, further research is needed to identify how individually based therapeutic and supportive work can be enhanced (Wong, 2006, p. 133).

The literature, then, indicates the importance of helping substance-abusing clients build and expand their social support network with people outside a treatment facility, which can also be an important role for social workers. Measuring the level of social support was an important task for the present study.

Researchers such as Cohen and Syme (1985) have written about the importance of social support as a mechanism that can both prevent disease and facilitate the recovery from disease. Given the conceptualization of substance use disorders as a disease, social support is an appropriate topic for the present discussion. With this model of social support as part of their conceptualization, Zimet, Zimet, and Farley (1988) developed the Multidimensional Scale of Perceived Social Support. The tool was developed to focus on the subjective experience of social support from family, friends and significant others. The tool consists of twelve questions using a seven point Likert scale from strongly agree to strongly disagree. The scale was found to be both a valid and reliable tool to measure perceived social support. In their validation of the 
instrument, test subjects were able to distinguish between social support among the three foci of the instrument (family, friends and significant others). In a confirmatory study Zimet, Powell, Farley, Werkman, and Berkoff (1990) tested the reliability and validity for three groups: pregnant women, adolescents living in Europe with their families, and pediatric residents working in Cleveland hospital. The scale was found to have good internal reliability across the three groups (Cronbach Alpha scores of .92 for the pregnant women, .84 for the adolescents living in Europe, and .90 for the pediatric residents). The scale has been validated by other research, including use in a study on social support with a predominantly African-American sample (Canty-Mitchell, 2000). The scale has also been used in other substance use research (Avants, Warburton, and Margolin, 2001; Stanton-Tindall, Royse, \& Leukfeld, (2007).

\section{Spirituality}

Just as AA can provide social support, so can it provide another key component for recovery: spirituality. As previously discussed, spirituality is an omnipresent factor in 12-step meetings and 12-step facilitated treatment and has long been viewed as an important factor in a person's success in recovery (White, 1988). Step Two of the twelve steps of Alcoholics Anonymous states this well: "Came to believe that a Power greater than ourselves could restore us to sanity" (Alcoholics Anonymous, World Services, 1981, p. 5).

Academics have explored the importance of spirituality and religion. Empirical studies indicate that spirituality promotes a sense of well-being (Campbell, 1971, 1981) and is associated with abstinence from substance use (Bliss, 2007; Ellison, 1983; in Miller, 1998). While religion and spirituality are defined differently, the former has also 
been examined as a factor in recovery. Valliant and Milofsky (1982) studied the process of recovery better to understand alcoholism and keys to recovery. One of the variables examined, in a cohort of males ages 14 to 47 , was religious involvement in relationship to "secure abstinence" defined as three or more years of abstinence. Data revealed that among the group of men having found to be securely abstinent, $19 \%$ revealed experienced hope and self-esteem due to increased religious activities.

Ellison (1983) studied spirituality in an effort to understand its role in a person's overall well-being. Building on Campbell's work (1971, 1981), Ellison (1983) explored an additional measure of well-being, "the need for transcendence" (p.330), defining spirituality as "a non-physical dimension of awareness and experience" (p.330-331). He discussed how a person with disabilities could better manage his/her situation because he or she can "... interpret the suffering within the context of deeper positive meaning" (p. 332). Thus, the importance of spirituality, espoused by AA, has been corroborated through research.

Allport and Ross (1967) investigated the relationship between religious orientation and prejudice. As a part of this study, the authors distinguished between intrinsic versus extrinsic religious orientations. They defined that those with an intrinsic religious orientation internalize their religion and, as such, it becomes their "master motive" (p.434). They developed a scale comprised of a twelve- question extrinsic religious orientation scale and an eight-question intrinsic religious orientation scale. The scale was ultimately found to be a valid tool in distinguishing between different religious orientations. 
Taking the precedent set by Allport and Ross, Hodge $(2000,2001)$ investigated the intrinsic nature of spirituality as opposed to religion. He distinguished religion and spirituality by stating that:

... spirituality refers to an individual's relationship with God (or perceived transcendence), while religion is defined as a particular set of beliefs, practices, and rituals that have been developed in a community by people who share similar existential experiences of transcendent reality (Hodge, 2000, p.2).

From this distinction between religion and spirituality, Hodge sought to develop a scale that measured spirituality as its own entity and not embedded in a religious context as other scales had. Hodge developed the Intrinsic Spirituality Scale using, in part, items from the Allport and Ross scale, removing any references to religion. In addition, questions were derived from previous work by Allport and Ross (1967) on intrinsic motivation and from subsequent work on the same topic by Gorsuch, Mylvaganam, and Gorsuch (1997). The original scale was validated by comparing the responses from other validated scale. Most applicable to the current study are the questions asked regarding the amount of alcohol consumed, the frequency of intoxication, and the frequency of smoking. Hodge believed that an inverse relationship between level of substance use (alcohol and nicotine) and the level of a respondent's spirituality would be revealed; findings supported this hypothesis. The final validated scale contains six questions in which the respondents are given a sentence stem about a key component of spirituality and are asked to the complete the stem by selecting a scaled (0-10 or 10 to 0 ) response. 


\section{Physical Capital}

While peer-reviewed literature on the relevance of physical capital and recovery from substance use disorders is sparse, there are references to its importance in other literature. The United Nations published a report on the need to develop recovery capital with a focus on physical and financial capital (United Nations, Office on Drugs and Crime, 2008). The report defines physical and financial capital as being comprised of:

economic and financial assets (e.g., income, property, and investments), basic infrastructure, and producer goods such as tools and equipment) needed to support livelihoods: transport, secure shelter, water supply and sanitation, clean and affordable energy (p. 13).

The report discussed the importance of employment and cited several authors who noted the high rate of unemployment in individuals in drug treatment programs (Hser, Polinsky, Maglione \& Anglin, 1999). In addition, the report noted that those programs that provide services such as housing and employment support have better recovery outcomes than those programs that do not (Kaskutas, Ammon \& Wesiner, 2004). Finally, the report stated the need for people in recovery to have a source of income due to the high rates of unemployment, inadequate job skills and poor pay (McLellan, Lewis, O'Brien \& Kleber, 2000). The UN report also noted the importance of shelter and housing for those recovering from alcohol dependence, calling housing "an important support to motivate and aid recovery" (United Nations, Office on Drugs and Crime 2008, p. 31). 
In another study (Dennis, Foss \& Scott, 2007), researchers examined factors in addition to abstinence from substances that contributed to long-term recovery. While the study examined many recovery indicators, three indicators are salient to the present discussion of physical capital: employment, family income, and housing. The indicators were examined at recovery periods of one to twelve months, one to three years, three to five years and five or more years. Those results were then compared to findings at year eight of the study. The respondents were from various levels of care, including ten outpatient programs, five intensive outpatient programs, three methadone maintenance programs, two short-term inpatient programs, one long-term inpatient program, and one halfway house. The results revealed that years of abstinence were positively correlated with the number of days of work and income from employment. In addition, longer periods of recovery corresponded with families rising above the Health and Human Services poverty line. Likewise, increased length of recovery corresponded with an increased number of days housed. Therefore, and as would be expected, as length of recovery increased, key components of physical capital also increased. Physical capital can be an important component of ongoing abstinence.

\section{Recovery Capital: A Unifying Concept}

The domains that contribute to recovery including those just discussed are collectively referred to as recovery capital. These elements include social capital, defined as social support from friends and relatives, spirituality, the belief of a higher transcendence, and physical capital. As previously mentioned, the concept of recovery capital evolved out of research performed by Cloud and Granfield (1999). They conducted 46 interviews with people recovering from addiction (alcohol, cocaine, heroin, 
barbiturates, amphetamines, or combinations of those substances). Interestingly, none of the people in the study had entered treatment or participated in any twelve steps meeting such as Alcoholics Anonymous., The authors relate a recovery story told by Benjamin Rush as an example of this natural recovery:

A farmer in England, who has been many years in the practice of coming home intoxicated, from the market town, one day observed appearances of rain, while he was in market. His hay was cut and ready to be housed. To save it, he returned in haste to his farm, before he had taken his customary grog. Upon coming into his house, one of his children, a boy of six years old, ran to his mother, and cried out. "Oh! [sic] mother, father is come home, and he is not drunk!" The father, who heard this exclamation, was so severely rebuked by it, that he suddenly became a sober man (Rush, 1805 as quoted in Cloud and Granfield, 1999, p.).

This story, although over 200 years old, shows the early understanding how recovery can occur through social support (son supporting father) that can result in spontaneous recovery. Since the original work of Cloud and Granfield, other researchers have incorporated recovery capital domains as those discussed above, including participation in AA meetings.

Laudet, Morgen and White (2006) performed extensive quantitative analyses on recovery capital. The authors studied a cohort of 353 people from New York City who were recovering from substance dependence (the majority of the respondents used crack or heroin0. The study sought to explore the buffering effects of recovery capital from stress and promote quality of life. The authors investigated the relationship 
between length of recovery, social support, recovery support, spirituality, religiousness, 12-step attendance, 12-step affiliation, and life meaning and their effect of buffering stress, leading to higher quality of life. Their findings revealed that social support, religiousness, 12-step affiliation, and life meaning were, in fact, found to buffer stress, and were correlated with longer recovery time and higher quality of life.

Laudet and White (2008) further examined these and other recovery capital domains to determine if they were predictors of sustained recovery in a cohort of respondents whose primary substances used were crack cocaine and heroin. The domains in their full model of recovery capital included recovery support, general social support, spirituality, life meaning, religiousness, and twelve-step affiliation. Recovery support was measured using the Social Support Recovery Scale while general support was measured using Social Support Appraisal Scale. The authors reported that the full recovery capital model predicted sustained recovery, confirming their hypothesis. However, when individual recovery capital domains were examined, spirituality was a significant predictor at 18-23 months and three plus years while all other domain findings were not significant. The authors also hypothesized that social support (operationalized as general support and recovery support) would be a predictor of shortterm recovery (six months or less). Their findings revealed that only general support was a significant predictor.

Since these findings conflict with past studies that revealed that social support was an important factor in recovery, the authors suggested that the role of social support should be examined further with follow-up studies. The authors also reported statistically significant multicollinearity between variables. Specifically, general social 
support was significantly correlated with twelve-step involvement; twelve-step involvement was significantly correlated with spirituality; general social support was significantly correlated with spirituality, indicating the need for assessing multicollinearity in the proposed study.

More recently, researchers (Groshkova, Best \& White, 2012) developed a scale to measure the level of recovery capital in recovering individuals. The scale, called the Assessment of Recovery Capital (ARC), contains fifty items covering ten domains of recovery capital. The ten domains include substance use and sobriety, psychological health, physical health, citizenship and community involvement, social support, meaningful activities, housing and safety, risk-taking, coping and life functioning and recovery experience. The domains of the scale were based on the results of focus groups and interviews with recovery professionals and clients.

To test the validity of the scale, the researchers administered the survey to two main cohorts: those engaged in treatment $(n=45)$ and a group currently in recovery, not in treatment $(n=176)$ in England. Concurrent validity was tested using the World Health Organization Quality of Life Scale-BREF (WHOQOL-BREF) and the analysis revealed statistically significant correlations between the four domains of the WHOQOL-BREF and the overall ARC score. Interestingly, in this scale, there are no direct references to spirituality or AA, scale both of which have been shown to be key factors in recovery. While the ARC provides a validated means to measure recovery capital, its lack of inclusion of two of the major domains of recovery capital limits its applicability to the present study, but does provide a useful comparison. 
In addition to this scale, White and Cloud (2008) developed a matrix to show the relationship between recovery capital and the severity which is used to determine treatment need for persons with co-occurring substance use disorders and mental illness. The matrix demonstrates the need for additional recovery capital as problems intensify. The authors note this has significant implications for treatment matching (reprinted with permission (White \& Cloud, 2008).

\section{Recovery Capital, Self-Efficacy, and the Ecological Perspective}

As Laudet and White (2008) note, recovery from substance dependence is an extremely complex process that includes many environmental factors and, as such, is grounded in a person and environment or ecological theory. Since 1971, Bandura has shown that self-efficacy is a crucial factor in a person's success. Recovery researchers have successfully applied this theory to better understand the reasons for relapse. Jane Addams clearly understood the importance of environmental influences such as poverty (lack of physical capital) on behavior. Later social work practitioners such as Perlman appreciated the fact that while there may be many internal problems to address, if the environmental issues that are affecting the client are ignored, then a client will continue to struggle. More recently, Germain and Gitterman (2008) described the relationship between the person and the environment and life stressors: “. . . the stressor-stresscoping paradigm takes into account the characteristics of the person and the operation of the environment, as well as the exchange between them" (p. 10). The ecological perspective deepens the concept of recovery capital. Environmental factors such as the recovery capital domains of social support, affiliation with Alcoholics Anonymous and physical capital can help a person better cope with stressors that can lead to relapse. 
Understanding social problems through such a lens is an important contribution to social work scholarship. The proposed research explores how these environmental factors, along with intrapersonal factor of spirituality, impact recovery. In addition, the research investigated the relationship between treatment and recovery.

Because substance use disorders are so common and the burden so great, the focus of the research described here is on recovery from alcohol and drug use disorder and the role of recovery capital. The expectation was that this research would provide new insights specific to substance use and recovery capital.

\section{Research Questions and Hypotheses}

With social capital and ecological theory acting as solid foundations, recovery capital offers a construct to investigate recovery from substance dependence. As selfefficacy theory provides the means to measure the effect of recovery capital, the following research questions and hypotheses look to unveil a better understanding of how people recover.

\section{Research Questions:}

Q1. Does recovery capital affect the level of self-efficacy to abstain from alcohol use during the first year of recovery?

Q2. Does recovery capital affect the level of self-efficacy to abstain from drug use during the first year of recovery?

Q3. Does substance abuse treatment affect recovery capital and level of selfefficacy to abstain from alcohol use during the first year of recovery?

Q4. Does substance abuse treatment affect recovery capital and level of selfefficacy to abstain from drug use during the first year of recovery? 


\section{Research Hypotheses}

H1. The greater the level of recovery capital, the higher the level of self-efficacy to abstain from alcohol use during the first year of recovery.

H2. The greater the level of recovery capital, the higher the level of self-efficacy to abstain from drug use during the first year of recovery.

H3. The effect of recovery capital on the level of self-efficacy to abstain from alcohol use is moderated by completion of substance abuse treatment during the first year of recovery.

H4. The effect of recovery capital on the level of self-efficacy to abstain from drug use is moderated by completion of past substance abuse treatment during the first year of recovery. 


\section{Chapter Two: Methodology}

\section{Original Plan}

Initially, the plan was to survey clients with a diagnosis of alcohol dependence, who had recently relapsed and who were currently in treatment programs. Many of the clients screened for the study were also diagnosed with dependence on other drugs in addition to alcohol. The inclusion criteria was then changed to include potential respondents with drug dependence diagnoses in addition to or instead of alcohol dependence diagnoses. As recruitment remained problematic, additional changes to the study were made and eventually the researchers decided that the following methodology would better facilitate study enrollment.

\section{Design and Rationale}

An observational design with a survey (see Appendix A) was employed to test the associations of the overall recovery capital model and individual recovery capital factors experienced by respondents during the first year of recovery from substance use (alcohol or drugs). A retrospective design was used so that responses to the survey questions would reflect on a common time in recovery, thus allowing for a valid comparison of the respondents. In many studies that examine recovery, length of abstinence is often used to measure the quality of a respondent's recovery. However, in this present study, since the length of the respondents' recovery time is variable and each respondent could rate his or her length of abstinence differently, abstinence selfefficacy was used as a uniform measure of recovery. The survey comprised both closeended and open-ended questions, and was administrated online using a secure 
website: Qualtrics. The closed-ended questions primarily asked about demographics, history of drug and alcohol use, and assessments for factors related to the recovery process. The open-ended questions were designed to foster a discussion about the reasons for their recovery difficulties and successes.

\section{Sampling and Data Collection Procedures}

A convenience sample of respondents was recruited from members of a local recovery community organization and a nationally based recovery community organization. The local organization, Connecticut Community for Addiction Recovery (CCAR), provides advocacy, training and recovery-based services for individuals in recovery from substance use problems. CCAR was founded in 1998. CCAR has over 10,000 participants including staff, volunteers, and others actively engaged in the organization (P.Valentine, personal communication, February 28,2015$)$. The nationally based organization, Faces and Voices of Recovery, also provides recovery advocacy and promotes the creation of policies to remove the stigma of substance use disorders. Faces and Voices of Recovery was founded in 2001 and boasts a nationwide membership of over 25,000 people (FaceandVoicesofRecovery.org, 2015) and with an outreach to 34,000 people who receive their newsletter and 26,000 Facebook followers (J. Gillen, personal communication, April 27, 2015). The survey was available through a link embedded in Faces and Voices of Recovery Facebook page, CCAR's newsletter and emails sent by the CCAR administration. Potential respondents accessed and completed the online survey from that link, which led them to the Qualtrics website.

The survey was accessed via an online link to the secure Qualtrics website. Qualtrics is UCONN affiliated company and website that provides researchers with the 
ability to create secure, easily accessible, and user-friendly on-line surveys. The survey was designed to be comprehensive, while also being sensitive to the personal nature of the questions being asked about respondents' alcohol and illegal drug use.

\section{Data collection and context}

All survey responses were secured in the Qualtrics website. The names of the respondents were not revealed to the researchers during data collection or any other phase of the study. Names of respondents were not included on the survey and survey questions were designed to avoid collecting any identifying information. Through Qualtrics, the researchers anonymized all responses. Qualtrics did not collect any identifying information including IP addresses. The data in Qualtrics were directly uploaded to SPSS for data analysis. Data were accessible to the researchers only. All data will be destroyed five years after the study is completed

\section{Inclusion/Exclusion Criteria}

To be included in this study, respondents were required to be at least eighteen years old, to have had at least an eighth-grade education, to be in recovery from use of substances (alcohol or drugs), and were able to read and write in English. The researchers excluded potential respondents who were under 18 years old because adolescents younger than 18 years old could have vastly different recovery experiences. Thus, the age group was limited to older than 18 to control for this potential variability. Questions at the beginning of the study screened for these criteria. Those who did not meet the criteria were automatically skipped to the end of the survey. 


\section{Measures for Background/Demographic information}

Demographic information including gender, race and ethnicity, and employment and salary were collected. Questions commonly used by the United States Census Bureau (2010) were used in this section. Physical capital was measured using a survey question developed by the present researchers. The brief survey captured information on the respondents' living and overall financial situation during their first year of recovery. Those responses were measured as a proxy for physical capital.

\section{History of Substance Use}

Alcohol and drug use, recovery history, and treatment history were collected to understand the substance use and recovery history of the respondents. Questions regarding substance use were from the National Survey on Drug Use and Health (2010), which is a public domain survey. Respondents reported the last month and year of use of alcohol as well as cocaine, non-prescribed opiates/pain relievers, nonprescribed marijuana, and non-prescribed benzodiazepines (depressants). The additional substances were limited to those four due to their frequency of use among substance users (NIDA, 2009).

\section{Affiliation with Alcoholics Anonymous}

Respondents' investment in 12-step groups was measured using the Alcoholics Anonymous Affiliation Scale (AAAS) (Humphreys, 1998) which measures a person's investment in AA, and fits well with the Glaeser, et al. (2002) economic framework. This validated scale was comprised of nine Likert-type items from which a summary score was calculated. Several dimensions of participation in AA activities, including sponsorship, AA related activities, and spirituality were measured using this survey. 
Since the respondents for the present study were not in treatment, one of the advantages in adapting this scale to measure $\mathrm{AA}$ investment/involvement is that this scale had been cross-validated in different populations, including individuals not in substance abuse treatment (Humphreys, 1998). The tool was found to be reliable (Humphreys, 1998) with a Cronbach's alpha score of .84. In addition, the authors noted that their findings, consistent with Morgenstern (1997), revealed that AA affiliation can be pared down to one factor (AA affiliation) rather than analyzing two separate factors (AA attendance and involvement) as suggested by Tonigan, Connors and Miller (1996).

While the original survey contained nine Likert-type questions, the researchers for this study removed the first two questions, which asks about the number of $A A$ meetings attended in the past twelve months and the current lifetime number of meetings attended. These questions were not used because the present study is retrospective, investigating the first year of recovery for each respondent. Due to the time being investigated, the questions used were modified, asking respondents to reflect on their first year of recovery. Because of this change, the scores for respondents would be lower than the results in other studies using the full nine-item scale. The score was calculated by adding the number of "yes" responses for each respondent.

\section{Spirituality}

Spirituality was measured using the Intrinsic Spirituality Scale (ISS, Hodge, 2003). This public domain scale included six questions designed to measure the subjective experience of spirituality in the respondents' lives. The scale has been found to be reliable (Cronbach's alpha=.96) (Hodge, 2003). In developing the survey, Hodge 
argued that other spirituality surveys had used religious connotations, especially those that referenced "god," which the ISS does not. Since Alcoholics Anonymous focuses on spirituality rather than religion, this survey is highly relevant to the proposed study. Other spirituality scales found a negative correlation with substance use and spirituality. Therefore, for Hodge's survey, concurrent validation was performed and, like other scales, spirituality was negatively correlated with substance use factors: namely, alcohol use, binge drinking, and tobacco use. For the present study, the survey questions were revised to gather information about the respondents' first year of recovery. As developed by Hodge, the Likert scaled questions had varied ranking schemes (some 1 to 10 and others 10 to 1 ) and different anchors; three questions were analyzed using reverse scoring. Because the researchers were concerned that respondents could be confused by this construction, a non-scored sample question was included to help respondents become accustomed to the question type. A mean summary score for spirituality was calculated for each respondent.

\section{Social Support}

Social support was measured using the Multidimensional Scale of Perceived Social Support (Zimet, Zimet \&Farley, 1988). Using a model proposed by Cohen and Syme (1985), the authors developed the scale, focusing on the subjective experience of social support from family, friends and significant others. The tool consists of twelve statements, using a seven point Likert scale from strongly disagree to strongly agree. The scale was found to be both valid and reliable (Cronbach's alpha=.88) for perceived social support (Zimet, et al., 1988). The questions in this survey were revised to ask 
about the level of support in the respondents' first year of recovery. A mean summary perceived social support score was calculated for each respondent.

\section{Substance Use Abstinence Self-Efficacy}

Drug abstinence self-efficacy was measured using the Drug Abstinence Self-Efficacy Scale (Hiller, Broome, Knight, \& Simpson, 2000). This survey was used to collect data for one of the two dependent variables in this study, drug abstinence self-efficacy. Respondents were given 20 different scenarios in which their abstinence was threatened. Using a five point Likert scale, each respondent rates his/her belief in their ability to abstain from drug use for each scenario using a range of one (not at all) to five (extremely). This tool has been found to be reliable (Hiller, et al., 2000) with Cronbach's Alpha scores for each subscale (Confidence subscales: Negative Affect .92;

Social/Positive .92; Physical/Other .89; Withdrawal/Urges .89. Temptation Subscales: Negative Affect .90; Social/Positive .87; Physical/Other .72; Withdrawal/Urges .83). As with the other surveys measuring the independent variables, these questions were revised to gather information on the respondents' first year of recovery. Only those respondents with a history of illicit drug use were asked to complete this section. Therefore, immediately prior to the Drug Abstinence Self-Efficacy scale, respondents were asked if they were in recovery from drug addiction. An endorsement of this question led them to the survey. If the respondents did not endorse that question, they were skipped to the next set of questions. A mean score was computed for each respondent.

Likewise, alcohol abstinence self-efficacy was measured using the Alcohol Abstinence Self-Efficacy Scale (DiClemente, Carbonari, Montgomery, \& Hughes, 1994). 
Respondents were given 20 different scenarios in which their abstinence may be threatened. Using a five point Likert scale, each respondent rates his/her belief in their ability to abstain from alcohol use for each scenario using a range of one (not at all) to five (extremely). This tool has been found to be reliable (DiClemente, et al., 1994) with Cronbach's Alpha scores for each subscale (Confidence subscales: Negative Affect .88; Social/Positive .82; Physical/Other .83; Withdrawal/Urges .81. Temptation Subscales: Negative Affect .99; Social/Positive .86; Physical/Other .60; Withdrawal/Urges .70. Only those respondents with a history of alcohol use were asked to complete this section. Therefore, immediately prior to the Alcohol Abstinence Self-Efficacy scale, respondents were questioned if they were in recovery from alcoholism. An endorsement of this question, led them to the survey. If the respondents did not endorse that question, they were skipped to the next set of questions. A mean score was computed for each respondent.

\section{Data Analysis: Hypotheses 1 and 2 (Figure 1)}

H1. The greater the level of recovery capital (independent variables), the higher the level of self-efficacy to abstain from alcohol use (dependent variable) during the first year of recovery.

H2. The greater the level of recovery capital, the higher the level of self-efficacy to abstain from drug use (dependent variable) during the first year of recovery.

\section{Independent variables}

1. Indexed full recovery capital model

2. Alcoholics Anonymous Affiliation Scale measuring investment in AA (dichotomous scoring) 
3. The Multidimensional Scale of Perceived Social Support measuring emotional social support

4. Physical capital measured using the financial stability questions developed by the researchers

5. Intrinsic Spirituality Scale measuring level of spirituality

Dependent Variables operationalized as alcohol abstinence self-efficacy and drug abstinence self-efficacy

1. Alcohol abstinence self-efficacy as measured by Alcohol Abstinence Self-Efficacy Scale

2. Drug abstinence self-efficacy as measured by the Drug Abstinence Self-Efficacy Scale.

\section{Covariates for Hypotheses 1 and 2}

1. Gender,

2. Race and ethnicity,

3. Age, and

4. Education

\section{Method of Analysis}

The statistical analyses were carried out in a two-step process. First, preliminary analyses were conducted to examine the data for frequency distributions, demographic differences, psychometric properties, and the zero-order intercorrelations among all of the major variables. Second, a series of hierarchical regression analyses were used to test the association of recovery capital and self-efficacy of substance use abstinence. The first set of the analyses examined the influence of affiliation with AA, spirituality, financial status, and social support on self-efficacy of substance use abstinence 
(hypotheses 1 and 2). In the first step, demographic variables were entered, followed at the second step by the four individual recovery factors.

Gender was dummy coded with male as the reference group (male $=0$, and female=1). Race and ethnicity were originally categorical variables and were dichotomized into White vs all other races, with White as the reference group (White, non-Hispanic $=1$, all other races $=0$ ) for analyses purposes to increase statistical power. After examining the empirical distribution of age groups, two dummy variables were created to compare the differences between younger age group (less than 45 years old) and middle age group (45-59 years old); and older age group (older than 59 years old) and middle age. Similarly, based on the observed frequency of educational level from this study, education was also dichotomized with one group have less than college education, and the other group with college or more years of education (less than college $=0$, college or higher=1).

For each step, the R squared changes were computed to determine the incremental variances that can be accounted for by the additional variables. The second set of the hierarchical regressions examined the association of recovery capital index and the substance abuse abstinence self-efficacy scores. Similar to the first set of hierarchical regressions, demographic variables were entered at the first to control for their influence on the substance abuse abstinence self-efficacy scores. The recovery capital index score was entered as the second step. The goal for the final set of hierarchical regression analyses was to determine whether receiving substance abuse treatment moderated the effect of recovery capital index score on the substance abuse efficacy scores (hypothesis $3 \& 4$ ). A treatment by recovery capital interaction term was 
computed and entered in the hierarchical regression as the last step. A statistically significant interaction term would suggest that the effect of recovery capital on efficacy scores depended on whether participants received substance abuse treatment or not.

\section{Data Analysis: Hypotheses 3 and 4 (Figure 2)}

H3. The effect of recovery capital ) (independent variables) on the level of selfefficacy to abstain from alcohol use (dependent variable) is moderated by completion of substance abuse treatment during the first year of recovery.

H4. The effect of recovery capital (operationalized as Alcoholics Anonymous affiliation, social support, physical capital, and spirituality) on the level of selfefficacy to abstain from drug use (dependent variable) is moderated by completion of past substance abuse treatment during the first year of recovery.

\section{Independent variable}

1. Indexed recovery capital model

Dependent Variables operationalized as alcohol abstinence self-efficacy and drug abstinence self-efficacy

1. Alcohol abstinence self-efficacy as measured by Alcohol Abstinence Self-Efficacy Scale

2. Drug abstinence self-efficacy as measured by the Drug Abstinence Self-Efficacy Scale.

\section{Moderating Variable}

Substance abuse treatment 


\section{Covariates}

1. Gender

2. Race and ethnicity

3. Age and

4. Education

\section{Method of Analysis:}

Through multiple regression, the interaction of substance abuse treatment and recovery capital on recovery were analyzed. Baron and Kenny's (1986) statistical test to determine moderator effects of a variable was used. The interaction of the hypothesized moderator variable (substance abuse treatment completion) and recovery capital (the predictor variable) on alcohol and drug abstinence self-efficacy was analyzed. As proposed by Baron and Kenny, if the effect of the moderator was statistically significant, the null hypothesis would be rejected; treatment acts a moderator for the effect of recovery capital on recovery.

Gender was dummy coded with male as the reference group (male $=0$, and female=1). Race and ethnicity were originally categorical variables and were dichotomized into White vs all other races, with White as the reference group (White, non-Hispanic $=1$, all other races $=0$ ) for analytical purposes to increase statistical power. After examining the empirical distribution of age groups, two dummy variables were created to compare the differences between younger age group (less than 45 years old) and middle age group (45-59 years old); and older age group (older than 59 years old) and middle age. Similarly, based on the observed frequency of educational level from this study, education was also dichotomized with one group have less than college 
education, and the other group with college or more years of education (less than college $=0$, college or higher $=1$ ) .

\section{Open-Ended Research Questions}

In an effort to understand recovery better, seven open-ended questions were asked at points in the survey relevant to the topic of the question:

1. What was most helpful about attending AA, NA or other 12-step meetings?

2. What was the least helpful about attending AA, NA or other 12-step meetings?

3. Why did you not attend AA, NA or other 12-step meetings?

4. What was most beneficial in the treatment you received?

5. What was least beneficial to the treatment your received?

6. Why did you not participate in treatment?

7. For this final question, please consider the entire course of your current recovery, not just the first year. What most worked for you in your recovery?

As with all the data in this study, responses to these questions were securely uploaded from the Qualtrics website to the SPSS database. The non-identified responses were copied into Microsoft Word for analysis. The analysis explored common recovery-related themes. The researchers anticipated that the responses would reveal the salience of the recovery capital domains. 


\section{Ethical Considerations}

Besides the time needed to complete the survey, it was anticipated that there would be no other inconveniences to the respondents. The level of risk involved in participating in this study was considered minimal. However, recalling past substance use may have created uncomfortable thoughts and feelings. To minimize this risk, respondents were informed prior to starting the survey that if they experienced any discomfort, that they could skip any questions and could choose to end the survey at any time. As noted, the survey was anonymous. Names and any other identifying information, including IP addresses, were not collected.

Many of the questions asked in the survey were written from a strengthsbased perspective, focusing on those factors that help respondents remain in recovery. Those questions that refer to past substance use were minimized and are very common questions in substance use surveys. It was anticipated that respondents would be familiar with such questions. Therefore, there was minimal risk of any of any discomfort. As stated, if any respondent did experience discomfort, an again s/he could choose to end the survey at any time, therefore further reducing risk.

There were no economic costs to the participants. The participants who completed the study were given the opportunity to enter a drawing for a $\$ 25.00$ gift card to Starbucks. If a respondent chose to enter the drawing, s/he clicked a link embedded in the study survey that was linked to a separate Qualtrics survey. This second survey simply asked the respondent to enter his/her email address. The email address served as the entry into the drawing. Upon completion of the 
study, one email address was randomly drawn as the winner of the gift card. The student researcher contacted the winner via email to obtain an address to send the gift card.

The first page of the online survey served as an unsigned information sheet. Respondents had to agree with the contents of the information sheet before proceeding with the survey. If respondents decided that they did not agree with the information sheet, they were directed to the end of the survey and were done. It was anticipated that respondents would possess the minimal skills necessary for appropriate decision making given the exclusionary criteria. 


\section{Chapter Three: Findings}

\section{Descriptive Statistics}

\section{Demographics. (Table 1)}

A sample of 263 respondents were included in the analysis of this study. The estimated number of people who could access the survey through either Facebook, emails, or newsletters was 44,000 . Thus, $.6 \%$ of all possible respondents completed the survey. No respondents were excluded from the study. The respondents were primarily White and non-Hispanic, female and between the ages of 45-59. Most of the respondents were married or in a civil union (43\%) and were also highly educated, with $58 \%$ having a college education or greater. The majority of the respondents were employed (79), with $75 \%$ with an annual income of at least $\$ 25,000$.

\section{Drug and Alcohol Related Descriptives (Table 2)}

Findings revealed that the cohort studied began using alcohol and/or drugs at a young age (e.g., alcohol, age 12, and cocaine, age 16). Not surprisingly, the most common drug of choice was alcohol (31.9\%), followed by opiates (14.1\%), and cocaine (12.2\%). Only 106 of the respondents endorsed completing treatment, with 135 respondents failing to answer the question related to completing treatment. Length of time in treatment during the first year of recovery varied greatly with $16 \%$ reporting being in treatment the entire 12 months of the first year of recovery and $13 \%$ in treatment less than three months. The average current length of recovery was impressive at 16 years, with $46 \%$ respondents stating that they were in recovery from 
alcohol use, $43 \%$ stating recovery from drug use and $29 \%$ in recovery from both alcohol and drugs.

Table 1 Demographics

\begin{tabular}{|c|c|c|}
\hline Characteristic & $\mathrm{n}$ & $\%$ \\
\hline Age $\mathrm{N}=254$ & 10 & 4 \\
\hline $18-30$ & 54 & 21 \\
\hline $31-44$ & 129 & 51 \\
\hline $45-59$ & 59 & 23 \\
\hline $60-74$ & 58 & 23 \\
\hline 75 or older & 3 & 1.2 \\
\hline \multicolumn{3}{|l|}{ Gender N=236 } \\
\hline Male & 90 & 37 \\
\hline Female & 146 & 62 \\
\hline \multicolumn{3}{|l|}{ Race $\mathrm{N}=263$} \\
\hline $\begin{array}{l}\text { White } \\
\text { African-American } \\
\text { Asian } \\
\text { Native-American } \\
\text { Native Hawaiian } \\
\text { Other } \\
\text { Not Known } \\
\text { Ethnicity }\end{array}$ & $\begin{array}{c}176 \\
44 \\
3 \\
9 \\
1 \\
31 \\
1\end{array}$ & $\begin{array}{l}67 \\
17 \\
1.1 \\
3.4 \\
.4 \\
12 \\
.4\end{array}$ \\
\hline Spanish/Hispanic/Latino & 28 & 11 \\
\hline \multicolumn{3}{|l|}{ Marital Status N=251 } \\
\hline Single, Never Married & 39 & 16 \\
\hline Married or Civil Union & 114 & 45 \\
\hline Divorced & 58 & 23 \\
\hline Separated & 5 & 2 \\
\hline Widowed & 7 & 3 \\
\hline
\end{tabular}




\begin{tabular}{lcc}
\hline Characteristic & $\mathrm{n}$ & $\%$ \\
\hline Committed romantic partner & 28 & 11 \\
Education N=254 & 3 & 1.2 \\
Junior high/middle school or less & 23 & 9 \\
High School & 80 & 32 \\
Some College & 148 & 58 \\
College or Beyond & & \\
Currently Employed N=251 & 199 & 79 \\
Yes & 52 & 20 \\
No & & \\
Income (previous year) N=187 & 47 & 25 \\
Under $\$ 25,000$ & 74 & 40 \\
$\$ 25,000-\$ 50,000$ & 45 & 24 \\
Over $\$ 50,0000$ but not over $\$ 100,000$ & 21 & 11 \\
$\$ 100,000$ or more &
\end{tabular}


Table 2

Drug, Alcohol, Treatment and Recovery-Related Descriptives

\begin{tabular}{|c|c|c|c|c|}
\hline Variable & $\mathbf{n}$ & $\%$ & Mean (SD) & Range \\
\hline Alcohol & 184 & & $12.2(4.2)$ & $2-24$ \\
\hline Cocaine (any form) & 176 & & $16.4(8.9)$ & $12-40$ \\
\hline $\begin{array}{l}\text { Marijuana (not } \\
\text { prescribed) }\end{array}$ & 178 & & $14.2(5.7)$ & $7-41$ \\
\hline $\begin{array}{l}\text { Tranquilizers and or } \\
\text { sedatives (not } \\
\text { prescribed) }\end{array}$ & 161 & & $13.3(10.5)$ & $9-51$ \\
\hline $\begin{array}{l}\text { Opiates (heroin, pain } \\
\text { killers not prescribed } \\
\text { and were used for the } \\
\text { feelings it caused) }\end{array}$ & 161 & & $14.2(11.8)$ & $12-45$ \\
\hline Other & 91 & & $12(10.1)$ & $7-39$ \\
\hline \multicolumn{5}{|l|}{ Drug of Choice $(N=179)$} \\
\hline Alcohol & 84 & 47 & & \\
\hline Cocaine (any form) & 32 & 18 & & \\
\hline $\begin{array}{l}\text { Marijuana (not } \\
\text { prescribed) }\end{array}$ & 10 & 6 & & \\
\hline $\begin{array}{l}\text { Tranquilizers and/or } \\
\text { sedatives (not } \\
\text { prescribed) }\end{array}$ & 1 & .6 & & \\
\hline $\begin{array}{l}\text { Opiates (heroin, pain } \\
\text { killers not prescribed } \\
\text { and were used for the } \\
\text { feelings it caused.) }\end{array}$ & 37 & 21 & & \\
\hline Other & 13 & 7 & & \\
\hline
\end{tabular}




\begin{tabular}{|c|c|c|c|c|}
\hline & $\mathbf{n}$ & $\%$ & Mean (SD) & Range \\
\hline \\
\hline \multicolumn{5}{|l|}{$\begin{array}{l}\text { Treatment Related } \\
\text { Variables }\end{array}$} \\
\hline $\begin{array}{l}\text { Treatment Completion } \\
\text { (first year of recovery) }\end{array}$ & 106 & & & \\
\hline None & 9 & 7 & & \\
\hline Less than 3 months & 35 & 27 & & \\
\hline $\begin{array}{l}\text { At least } 3 \text { months/less } \\
\text { than } 6\end{array}$ & 19 & 15 & & \\
\hline $\begin{array}{l}\text { At least } 6 \text { months/less } \\
\text { than } 9\end{array}$ & 16 & 12 & & \\
\hline $\begin{array}{l}\text { At least } 9 \text { months/less } \\
\text { than } 12\end{array}$ & 10 & 8 & & \\
\hline All 12 months & 41 & 32 & & \\
\hline $\begin{array}{l}\text { Recovery Related } \\
\text { Variables }\end{array}$ & & & & \\
\hline Years in recovery & 179 & & 16(10.6) & \\
\hline $\begin{array}{l}\text { In recovery from } \\
\text { alcoholism }(\mathrm{N}=159)\end{array}$ & 121 & 76 & & \\
\hline $\begin{array}{l}\text { In recovery from drug } \\
\text { use }(N=159)\end{array}$ & 114 & 72 & & \\
\hline $\begin{array}{l}\text { In recovery from both } \\
\text { alcohol and drug use }\end{array}$ & 76 & 48 & & \\
\hline
\end{tabular}




\section{Internal consistency/reliability of scales}

Cronbach Alpha scores were calculated for the scales used in the present study to determine the internal consistency/reliability. All scales were found to be acceptable with respect to their reliability.

Table 3

Cronbach Alpha Scores for Scales

\begin{tabular}{lc}
\hline \multicolumn{1}{c}{ Scale } & Cronbach's Alpha \\
\hline Multidimensional Scale of Perceived Social & .90 \\
Support (IV) & .78 \\
12-Step Affiliation Scale (IV) & .95 \\
Intrinsic Spirituality Scale (IV) & .97 \\
Alcohol Abstinence Efficacy Scale (DV) & .98 \\
Drug Abstinence Efficacy Scale (DV) & \\
\hline
\end{tabular}

\section{Descriptive Statistics for Recovery Capital Domains and Alcohol and Drug Self- Efficacy}

Correlations between the independent variables (Table 4) revealed that 12-

Step/AA affiliation and social support were positively and significantly correlated $(p<.05)$, spirituality and social support were positively and significantly correlated $(p<.05)$, and spirituality and 12-Step affiliation were positively and significantly correlated $(p<.01)$.The mean scores of the recovery capital domains were computed (Table 5). The scales to measure social support (Multidimensional Scale of Perceived Social Support, 12-Step Affiliation (Alcoholic Anonymous), and spirituality (Intrinsic Spirituality Scale) all revealed strong Cronbach Alpha scores. The mean abstinence self- efficacy scores (Table 6) for alcohol and drugs were similar at 3.6 (alcohol) and 3.7 (drugs). As with the other scales, the Cronbach Alpha scores were strong at .97 (alcohol) and .98 (drugs), showing high internal consistency. 
Table 4

Correlations for Independent Variables for Recovery Capital

\begin{tabular}{lcccc}
\hline \multicolumn{1}{c}{ Measure } & 1 & 2 & 3 & 4 \\
\hline 1. Social Support & -- & $.16^{*}$ & .08 & $.16^{*}$ \\
2. AA Affiliation & $.16^{*}$ & -- & .10 & $.22^{* *}$ \\
3. Financial & .08 & .10 & - & -.06 \\
4. Spirituality & $.16^{*}$ & $.22^{* *}$ & -.055 & -- \\
\hline
\end{tabular}

${ }^{*} p<.05,{ }^{*} p<.01$

Table 5

Mean scores of Recovery Capital Domains (IVs)

\begin{tabular}{lccccc}
\hline \multicolumn{1}{c}{ Domain } & $\mathrm{N}$ & Possible Range & $\mathrm{M}$ & $\mathrm{SD}$ & Range \\
\hline Social Support & 170 & $1-7$ & 4.82 & 1.21 & 5.58 \\
12-Step & 162 & $0-7$ & 5.08 & 1.63 & 1.63 \\
Affiliation & & & & & \\
Financial & 179 & $1-5$ & 3.09 & 1.25 & 4.00 \\
Spirituality & 169 & $0-10$ & 7.44 & 2.21 & 10.00 \\
\hline
\end{tabular}

Table 6

Substance Self-Efficacy Scores (DVs)

\begin{tabular}{lcll}
\hline Substance & $\mathrm{N}$ & $\mathrm{M}$ & $\mathrm{SD}$ \\
\hline Alcohol & 100 & 3.6 & .98 \\
Drugs & 113 & 3.7 & 1.0 \\
\hline
\end{tabular}

\section{Findings Related to Hypothesis 1}

Hypothesis 1: The greater the level of recovery capital, the higher the level of selfefficacy to abstain from alcohol use during the first year of recovery. Findings indicate that we can reject the null hypothesis.

To analyze the effect of recovery capital on self-efficacy to abstain from alcohol during the first year of recovery, multiple regression was performed (Table 7). Analysis 
revealed the indexed model was statistically significant $(F=3.40, p<.05)$. The effect of the recovery capital on alcohol abstinence efficacy was statistically significant $B=.766, t$ (4.234), $p<.001$. Thus, the data revealed that recovery capital plays an important and positive role in a person's belief that he or she is able to remain abstinent from alcohol use.

Analyses were performed and confirmed the assumption of no multicollinearity (Table 8) as all tolerance scores were well above .10. The recovery capital model, entering all four predictors individually (social support, 12-step affiliation, spirituality, and physical capital) was analyzed (Table 8). Findings revealed a positive correlation for the overall model with alcohol abstinence efficacy scores $(F=2.85, p<.01)$. When analyzing the effects of each of the predictors (recovery capital domains), spirituality, $(B=.12, t(2.39), p<.05)$ and 12-Step Affiliation $(B=19, t(2.78), p<.01)$ were statistically significant predictors of alcohol abstinence self-efficacy. Financial situation (physical capital proxy) and social support were not statistically significant predictors for alcohol use self-efficacy. In summary, this analysis examined each of the domains of recovery capital and their effect on a person's belief that he or she could remain abstinent from alcohol. The findings revealed that both spirituality and participating in 12-Step meetings played an important and positive role in the respondents' belief that they could abstain from alcohol use. However, social support and financial situation did not play a significant role. 


\section{Findings Related to Hypothesis 2}

Hypothesis 2: The greater the level of recovery capital, the higher the level of selfefficacy to abstain from drug use during the first year of recovery. Findings indicate that we can reject the null hypothesis.

The same analyses used for alcohol self-efficacy were performed to examine the effects of recovery capital on the drug abstinence self- efficacy. As with alcohol abstinence self-efficacy, analysis revealed the indexed recovery capital model was positively correlated with higher levels of drug self-efficacy, $(F=2.76, p<.05)$ (Table 7).

Thus, as with alcohol recovery, the data revealed that recovery capital plays an important and positive role in a person's belief that he or she is able to remain abstinent from drug use.

The recovery capital model, entering all four predictors individually (social support, 12-step affiliation, spirituality, and physical capital) was analyzed (Table 8). Analyses were performed and confirmed the assumption of no multicollinearity (Table 8) as all toleration scores were well above .10 . Findings revealed a positive correlation for the overall model with drug abstinence efficacy scores $(F=2.22, p<.05)$. Analysis revealed that social support was a statistically significant predictor of drug abstinence self-efficacy, $(B=.18, t(2.08) p<.05)$ (Table 8). Financial situation (physical capital proxy), spirituality, and 12-Step Affiliation were not statistically significant predictors for alcohol use self-efficacy. In summary, this analysis examined each of the domains of recovery capital and their effect on a person's belief that he or she could remain abstinent from drugs. The findings revealed that social support only played an 
important and positive role in the respondents' belief that they could abstain from drug use. However, participation in 12-Step meetings, spirituality, and the respondents' financial situation did not play a significant role.

\section{Findings Related to Hypothesis 3 and 4}

Hypothesis 3: The effect of recovery capital on the level of self-efficacy to abstain from alcohol use is moderated by the completion of substance abuse treatment during the first year of recovery. Findings indicate that we cannot reject the null hypothesis.

Hypothesis 4: The effect of recovery capital on the level of self-efficacy to abstain from drug use is moderated by completion of past substance abuse treatment during the first year of recovery. Findings indicate that we cannot reject the null hypothesis.

The analyses revealed that for the alcohol abstinence self-efficacy group (Table $9)$, the interaction of treatment was not statistically significant $(B=.120, t(-.248), p>.05)$. Therefore, treatment completion did not moderate the effect of recovery capital on alcohol abstinence self-efficacy. Likewise, for the drug abstinence self-efficacy group (Table 9), the interaction was not statistically significant $(B=.250 t(.67), p>.05)$. Therefore, treatment completion did not moderate the effect of recovery capital on drug abstinence self-efficacy. Of the participants enrolled in this study, 183 endorsed attending either outpatient or residential/inpatient treatment. Of those, 106 stated that they completed the treatment during that first year of recovery. Thus, while $40 \%$ of participants in the study completed treatment, findings did not reveal a significant interaction effect on recovery capital for the level of self-efficacy. In summary, treatment 
completion did not enhance the role of recovery capital on the respondents' belief that could abstain from alcohol and/or drugs.

Table 7

Hierarchical Regression Analysis Summary for the Indexed Recovery Capital Model Predicting Alcohol Abstinence Efficacy and Drug Abstinence Efficacy (Hypotheses 1 and 2)

\begin{tabular}{|c|c|c|c|c|}
\hline & $\begin{array}{c}\text { Alcohol Abstinence } \\
\text { Self-Efficacy } \\
n=100\end{array}$ & & $\begin{array}{c}\text { Drug Abstinence } \\
\text { Self-Efficacy } \\
n=113\end{array}$ & \\
\hline Predictor & B (SE) & $\Delta R^{2}$ & $\mathrm{~B}(\mathrm{SE})$ & $\Delta \mathrm{R}^{2}$ \\
\hline Step 1 & & .02 & & .04 \\
\hline Age $<45$ & $.33(.26)$ & & $.50(.23)$ & \\
\hline Age $>59$ & $-.11(.24)$ & & $.17(.25)$ & \\
\hline Education & $.17(.20)$ & & $.06(.19)$ & \\
\hline Gender & $-.16(.20)$ & & $-.17(.20)$ & \\
\hline Race & $.13(.22)$ & & $.20(.21)$ & \\
\hline Step 2 & & $.17^{* * *}$ & & $.11^{* *}$ \\
\hline $\begin{array}{l}\text { Recovery } \\
\text { Capital }\end{array}$ & $.77^{\star \star \star}(.18)$ & & $.65^{\star *}(.18)$ & \\
\hline Total $\mathrm{R}^{2}$ & .19 & & .14 & \\
\hline
\end{tabular}


Table 8

Hierarchical Regression Analysis Summary for Recovery Capital Variables Predicting Alcohol Abstinence Efficacy and Drug Abstinence Efficacy (Hypotheses 1 and 2)

\begin{tabular}{|c|c|c|c|c|c|c|}
\hline & $\begin{array}{c}\text { Alcohol } \\
\text { Abstinence } \\
\text { Self-Efficacy } \\
n=100\end{array}$ & & & $\begin{array}{c}\text { Drug } \\
\text { Abstinence } \\
\text { Self-Efficacy } \\
n=113\end{array}$ & & \\
\hline Predictor & $\mathrm{B}(\mathrm{SE})$ & $\Delta \mathrm{R}^{2}$ & Tolerance & B (SE) & $\Delta R^{2}$ & Tolerance \\
\hline Step 1 & & .03 & & & .03 & \\
\hline Age $<45$ & $.20(.27)$ & & & $.44(.24)$ & & \\
\hline Age $>59$ & $-.15(.24)$ & & & $.13(.26)$ & & \\
\hline Education & $.18(.20)$ & & & $.06(.20)$ & & \\
\hline Gender & $-.22(.20)$ & & & $-.20(.20)$ & & \\
\hline Race & $.10(.22)$ & & & $.17(.22)$ & & \\
\hline Step 2 & & $.22^{* * *}$ & & & $.16^{* *}$ & \\
\hline Spirituality & $.12^{*}(.05)$ & & .80 & $.09(.05)$ & & .83 \\
\hline Financial Situation & $.13(.08)$ & & .94 & $.12(.08)$ & & .96 \\
\hline Social Support & $.02(.08)$ & & .88 & $.18^{*}(.09)$ & & .89 \\
\hline 12-Step Affiliation & $.19(.07)^{\star *}$ & & .84 & $.09(.07)$ & & .85 \\
\hline Total $\mathrm{R}^{2}$ & .25 & & & .19 & & \\
\hline
\end{tabular}


Table 9

Hierarchical Regression Analysis Summary for Treatment Completion as a Moderator of Recovery Capital Variables in Predicting Alcohol Abstinence Efficacy and Drug Abstinence Efficacy (Hypotheses 3 and 4)

\begin{tabular}{|c|c|c|c|c|}
\hline & $\begin{array}{c}\text { Alcohol Abstinence } \\
\text { Self-Efficacy } \\
n=100\end{array}$ & & $\begin{array}{c}\text { Drug Abstinence } \\
\text { Self-Efficacy } \\
n=113\end{array}$ & \\
\hline Predictor & $\mathrm{B}(\mathrm{SE})$ & $\Delta R^{2}$ & B (SE) & $\Delta \mathrm{R}^{2}$ \\
\hline Step 1 & & 0.02 & & 0.04 \\
\hline Age $<45$ & $.33(.26)$ & & $.63(.24)^{\star *}$ & \\
\hline Age $>59$ & $-.10(.24)$ & & $.13(.24)$ & \\
\hline Education & $.14(.21)$ & & $-.02(.19)$ & \\
\hline Gender & $-.18(.20)$ & & $-.33(.20)$ & \\
\hline Race & $.13(.22)$ & & $.15(.20)$ & \\
\hline Step 2 & & $.17^{* *}$ & & $.16^{* *}$ \\
\hline Recovery Capital (index) & $.67(.28)^{*}$ & & $.57(.29)$ & \\
\hline Treatment Completion & $-.09(.22)$ & & $-.54(.22)^{*}$ & \\
\hline Treatment Interaction & $.19(.38)$ & & $.25(.38)$ & \\
\hline Total $\mathrm{R}^{2}$ & .20 & & .20 & \\
\hline
\end{tabular}




\section{Findings from Open-Ended Questions}

\section{Themes revealed with open-ended questions.}

What was most helpful about attending AA, NA or other 12-step meetings?

Respondents spoke of the support and fellowship they experienced through their attendance to 12-step meetings. Participants discussed AA/NA sponsorship as an important facet of that support.

People who heard me, loved me and supported me through the difficult process opportunity to learn new ways to live my life and SEEING the light and awakening in the lives of so many - they led the way.

[AA provided a] safe place. No drugs. Like minded people [wanting] to stay clean. Supportive literature. Sponsor relationship on a daily basis. A meeting to go to everyday of the week, sometimes [I] went to 4-6 meetings in a weekend just to stay safe. Several times members took me for coffee, bought me a sandwich and a couple of times gave me money for groceries without asking anything in return.

Respondents also often reflected on the structure that 12-step meetings provided. Related to this theme, participants mentioned the importance of leaning about recovery and the key elements of the 12-step philosophy

Because ALL of my friends used or drank, I needed positive people in my life to combat the loneliness (sic). I had somewhere to go every night at 8:30 until $10 \mathrm{pm}$. 
It gave me a set of directions to follow and identification with others was paramount. Any ... meeting you attended was strict adherence to the same principals. Consistency of the recovery message was key.

They taught me alcoholism was a disease. I felt like I belonged somewhere.

Talking and writing the 12 steps. Getting a sponsor and calling him. Male (sic) [sponsors] with males and female [sponsors] with females.

Learning the 12 steps.

Reading the Big Book.

Hearing the message of recovery.

Meeting others in recovery.

Networking telephone numbers.

Meetings were the social contact I looked forward to daily.

What was the least helpful about attending AA, NA or other 12-step meetings? When reflecting on the least helpful aspects of 12-step meetings, respondents spoke about some of the negativity they experienced. Common themes included concerns about gossip, negativity, "war stories" (reliving and sometimes glorifying past alcohol and drug use). In addition, respondents revealed cultural biases including difficulties experienced due to being Hispanic or female. Specifically, females complained about men "13-Stepping" (looking for a relationship at meetings). Finally, respondents expressed criticism about the perceived Christian perspective of 12-step meetings. 
Too much gossiping. Too much chaos in the meetings. Most people did not reach out to the new people like in the old days. NA is New York (sic) is a madhouse!

... god, at first I was so grateful to see it was possible to get sober. But it was very evident that the women and the program was a Christian based program. In my small community it is very WASP (sic). While I am a white female I soon felt different because I did not have a spiritual awakening. While I stayed I witnessed many who left. I witnessed young people especially chastised for talking about drug use. I volunteered to make coffee to force myself to go back. I wanted to stay sober in spite of AA (sic). My AA meetings are now as a volunteer in the jails. They told me I can have my own higher power but the "Lord's prayer" (sic) was said at every meeting.

AA is very male-focused. The book, the stories and experiences of [the] founders is heavily male and recommendations often work best for me (sic). I had to translate that into my experiences as a woman. I was blessed by a strong home group of women who also strived to use the program in a way women can relate to

There were little to no Spanish Speaking meetings and there were very few meetings of any kind in my immediate neighborhood - [l] had to travel in cars with others to get to some meetings. It was very frustrating when NA members would be disruptive and hold (sic) conversations while the meetings are going on. 
Why did you not attend AA, NA or other 12-step meetings?

Themes from respondents who did not attend AA or other 12-step meetings centered around their belief that attendance was not necessary or that they did not know about meetings. Other expressed concerns about the focus on spirituality, while other sought out other forms of assistance including traditional treatment and medical care.

I did not feel it was necessary

I didn't know there was such a thing, or else I would have jumped on this in a heartbeat (sic).

What was most beneficial in the treatment you received?

Respondents appreciated the support and expertise from the counselors who provided treatment. They also spoke highly of 12-step facilitated treatment and other types of treatment including outpatient, intensive outpatient, and medical including the prescribing of methadone and Suboxone. Finally, respondents expressed the structure that residential treatment provided, in addition to providing shelter.

28 day in patient treatment followed by 12 weeks relapse prevention out patient. I was also diagnosed with depression in the first month out of inpatient (sic) treatment. This involved counseling and psychiatry - (I) have been on medication ever (sic) since. I firmly believe ( $\mathrm{sic}$ ) if it had not been for the relapse prevention program I would have definitely not succeeded at my first attempt at recovery. 
The outpatient group therapy. A women's group. They helped me look at the reasons I used, face my denial and other defense mechanisms and kept me accountable. I am a nurse, in an alternative to discipline program. Was also required to do random drug test, go to 3-4 12 step meetings (sic)/week, have \& meet $\mathrm{w}$ a sponsor. I was monitored for 5 years. Saved my life!!

Support of my counselor, and my peers in my groups. As well as contingency management program I participated in ... having to take 3 toxicology screens per week helped keep accountable for my behaviors.

What was least beneficial to the treatment your received?

Overall, respondents stated that they struggled with the treatment protocols as well as having difficulties with staff.

Some of the 'rules' in treatment were very punitive. For example if you're (sic) assigned chores were not done you lost visiting time with families, loss of telephone time or you may have been given a demerit.

The walk we HAD to take in the mornings through the neighborhood (I Lived in) No one had to guess where I was or what I was doing...here come the alkies! 31 years ago substance abuse treatment had a stigma. Not so much today.

Why did you not participate in treatment?

In response to the question, respondents focused on an inability to attend due to financial, systemic or accessibility problems. Others stated that they chose AA instead. Finally, some respondents spoke of the shame they felt due to their addiction had prevented them from attending. 
I wasn't aware at the time of my early recovery on how I could go about getting in to a treatment without insurance. I wasn't aware of what 12-step or community support programs were at the time either. I called a residential and mental health crisis program (sic) at one time to try to get in for 24-hour monitoring. Not only was I denied services as a result of no insurance, but in my opinion, I was spoken to in a rude manner. I recall the receptionist told me to "sleep it off and just go to work in the morning" (sic). However, the following day, I didn't leave my house for three days. I didn't show up to any of my 3 jobs at that time and I didn't show up to any of my college courses. I was in bad shape.

For this final question, please consider the entire course of your current recovery, not just the first year. What most worked for you in your recovery?

Respondents repeated the themes of the importance of 12-step meetings, developing spirituality and the support of others and positive relationships.

The principle of not using NO MATTER WHAT! Building a very strong Spiritual base to my recovery [was important]. Creating a "family" that included people of my Latino culture in recovery throughout the major US cities and other Spanish (sic) speaking countries. Maintaining a network of people in long term recovery who supported each other through everything; loss of home, death of loved ones, major illnesses, loss of job, etc., etc.

Finding a spiritual connection in which I choose to call God, begging and asking for guidance and it worked! Also asking God to take away the desire to ever use Cocaine again and that happened for me. I used to attend AA and NA and because of Anonymity issues ( $\mathrm{sic}$ ) I stopped attending, I found God and made 
him the center of my recovery and l've been clean now for going on 7 years ( $\mathrm{sic}$ ) in October. Also wiping out who I thought were friends, My life consists of 2 clean close friends, my therapist and sponsor and my family (sic)!!

\section{Summary of Findings}

The findings revealed that the full recovery capital model was statistically significant for both alcohol and drug abstinence efficacy. When analyzing each of the

recovery capital domains, 12-Step Affiliation and spirituality were statistically significant factors in predicting alcohol abstinence efficacy. When analyzing each of the recovery capital domains, social support was statistically significant in predicting drug abstinence efficacy. Completion of treatment was not found to be a statistically significant moderator of recovery capital in predicting alcohol or drug abstinence efficacy. The responses to the open-ended questions reflected recovery capital themes including the importance of spirituality, social support, and attendance to 12-Step meetings. The responses to the open-ended questions also revealed the importance of treatment in general and, specifically, the importance of 12-Step facilitated treatment. 


\section{Chapter 4: Discussion}

\section{Study Limitations}

This study employed an electronic survey to collect data from a sample of respondents from two recovering community organizations, one local, and the other nationally based. The respondents' demographics reflect a sample that is dissimilar to the common characteristics of respondents in a typical addiction study. In many studies, such as the ones described here (e.g., Laudet \& White, 2006, 2008), respondents are generally in treatment or recently discharged from treatment, or have recently begun recovery. In the present study, however, many of the respondents had been in recovery for several years (average length of recovery time was 16.4 years). With this length of recovery, many respondents were employed (79\%) and earning competitive salaries (24\% earning at least $\$ 50,000$ annually), and were highly educated ( $58 \%$ with a college education or greater). As a result, this sample may not be representative of the general recovering population. While the study asked respondents to reflect back on their first year of recovery, the differences in the sample as compared to the commonly used sample of respondents cannot be overlooked as a potential source of respondent bias.

Related to this limitation, is the need for participants to respond to events that occurred during the first year of their recovery. This task would have required some participants to recall information from several years ago, most likely reducing the accuracy of their recall. To understand better the effect of such recall problems, a question was added to each of the efficacy scales to determine the participants' ability to recall the information from that first year. For recalling information for drug use self- 
efficacy, only $25.9 \%$ reported that they were either "extremely confident" or "very confident" that they could remember the details of their recovery. For recalling information on alcohol use self-efficacy, only 34.3 responded that they were either "extremely confident" or "very confident" that they could remember the details of their recovery. Therefore, recall bias could have played a role in the response.

In addition, when participants were asked if they were in recovery from drug addiction, 167 responded and 96 failed to respond. Similarly, 164 responded and 99 failed to respond that they were in recovery from alcoholism. While they had the option of choosing "yes" or "no" to each question, the question may have been misinterpreted and participants not endorsing drug or alcohol recovery may have simply left the question blank. To limit this confusion, the questions should have been required fields in the survey, forcing a "yes" or "no" answer. Such confusion on those questions could have contributed to the missing data in the self-efficacy scales.

Finally, while past research has shown that treatment has a positive impact on recovery, the present study did not reveal that treatment completion had a moderating effect on recovery capital in predicting drug or alcohol abstinence self-efficacy. While these finding may truly reveal no interaction, the researcher questions these findings due in part to the small sample size of respondents who completed treatment. The methodology could have included an analysis of the direct effect of treatment on recovery to determine if treatment completion had a main effect on alcohol and/or drug abstinence self-efficacy. Since the study only explored potential interaction effects, the potential influence of treatment was not investigated, limiting the scope of the present study. In addition, the study would have been enriched further had an analytical 
comparison of treatment modalities (e.g. outpatient vs. residential treatment) had been performed.

\section{Discussion of Recovery Capital and the Domains}

. The indexed recovery capital model had a significant effect on the respondents' level of self-efficacy on abstaining from both alcohol and drugs. This finding is consistent with past literature that analyzed similarly conceived recovery capital models (Marcenko \& Spence, 1995; Wong 2006). The most interesting findings, however, were revealed when each of the recovery capital domains were analyzed for their effect on the model (hypotheses one and two).

\section{Spirituality}

As discussed in Chapter One, the importance of spirituality in recovery has longbeen established, first anecdotally and later through research. The findings from this study for respondents who completed the alcohol self-efficacy scale $(n=100)$ revealed that spirituality is a statistically significant factor in their first year of recovery. Laudet, Morgen, and White (2006) found similar results in their research, which revealed that spirituality and other factors act as a buffer against stress. Bandura's self-efficacy theory and relapse theory offer further potential explanations of this positive relationship between self-efficacy and spirituality. As noted, research has shown that anxiety is a trigger for relapse and a return to drug and/or alcohol use (Marlatt, 1985; 2005). Recall that Bandura believed that there are four dimensions of efficacy expectations, including emotional arousal, including anxiety-induced arousal. One's ability to succeed in the face of perceived anxiety can result in increased self-efficacy. Perhaps here then, as in 
other studies (Laudet, 2006), spirituality acts as a buffer for people in recovery, reducing anxiety that early recovery may provoke. Respondents in this study discussed the importance of spirituality acting as means to support recovery: "Learning about my higher power, my powerlessness, and becoming spiritual for the first time in my life."

Conversely, data from the respondents $(n=113)$ who completed the Drug Abstinence Self-Efficacy Scale did not reveal this finding. This difference is somewhat surprising since past studies have shown that spirituality is an important factor in not only alcohol use recovery, but also drug use recovery (Laudet, Morgen \& White, 2006). Further investigation is needed to determine why these differences exist between the two groups. Understanding the differences in recovery from alcohol versus drugs and the importance of spirituality is crucial for the development of effective methods to treat recovering drug addicts. Often, the phrase "A drug is a drug is a drug" is heard by recovering individuals and professionals alike. This saying represents the idea that regardless of the drug being used, the effects on the brain are the same. While recent neuroscience advances are revealing the complexity of the effects of alcohol and other drugs on the brain (e.g., Koob \& Volkow, 2010), perhaps further differences between alcohol and drug recovery need to be explored.

As previously stated, respondents relayed both positive and negative comments on the role of spirituality.

Finding a spiritual connection in which I choose to call God, begging and asking for guidance and it worked! Also asking God to take away the desire to ever use Cocaine again and that happened for me. 
I had to learn to translate the Christian religion into what made sense to me - so the Christian (sic)-centric nature of AA/NA - I still translate today when at a meeting from the Christian (sic) to my spiritual understanding.

This dichotomy in respondents' views on spirituality may explain, in part, the results of the quantitative findings that spirituality was not a predictor of drug abstinence selfefficacy (Table 8).

\section{2-Step Meetings}

Alcoholics Anonymous, Narcotics Anonymous, and other 12-step meetings have historically provided recovering persons a place to connect with others and strengthen their recovery. Again, Bandura's self-efficacy theory can offer insights into this finding. Another dimension of self-efficacy expectations is vicarious experience. Alcoholics Anonymous and other 12-Step groups provide, in many cases, positive vicarious experiences that can promote self-efficacy and recovery. Such seems to be the case with the respondents in the present study, as one respondent stated:

AA meetings and the fellowship (sic). Alkathons, Dances, retreats, Pig Roasts, Being at meetings seeing others coming in from work, talking and talking about my days and fears etc. Conventions where I could see a sea of recovery, focusing on that piece of cake ... coin for one whole year of recovery. Wow!!! I still get goosey. 31 years and I remember. Each and every little event or problem in my life was discussed in meetings. Step meetings really made a big difference. Speaker meetings saved my life, I heard (sic) people talking about 
what I was thinking about in that first year and it changed my mind. I felt like I finally belonged. 31 years later...I still do.

Here the merits of being with other successfully recovering people who had similar experiences was crucial to the respondent's recovery process.

As discussed in Chapter 1, recovery capital is an ecological construct and as such contributes to social work scholarship. One can see this clearly in the significant role that 12-step meetings, as a domain of recovery capital, plays in a recovery. In their Life Model of Social Work Practice, Gitterman and Germain (2008) discuss environment fit concepts (p.55). The fit concept of exchanges enhances our understanding of the 12-Step meetings. According to the authors, exchanges are "Continuous transactions between people and their environments, in which each shapes the other over time." Clearly as evidenced by the comments made by respondents, the transactions, which occur during AA and NA meetings, have an important and positive effect on recovery. Those meetings provide an environment of care where participants' interactions benefit one another towards a common goal of sobriety.

In addition, findings from this study suggest that 12-Step meetings play an important role but, as in the case of spirituality, only for alcohol abstinence self-efficacy. Again, this difference is puzzling and contradicts the findings in other studies that show the importance of 12-step meetings for drug users (Gossup, Stewart \& Marsden (2007). In the Gossup, et al. study, the researchers tracked actual opiate abstinence over five years, rather than measure self-efficacy. The use of abstinence self-efficacy as a dependent variable rather than abstinence from alcohol and/or drugs could account for 
this discrepancy in the findings. One could speculate that the drug efficacy cohort did not have vicarious experiences that positively affected their recovery process. Some respondent comments reflect a negative experience in attending AA meeting:

People in AA claim to be open minded. However, I found this to be particularly untrue. They know the ONLY way to recover and if you disagree, well . . you're a loser. I know of people who relapsed and were uncomfortable with coming back because of ridicule (sic). I, myself was dubbed the "Relapse Queen" because I struggled

The fact that there were so many dealers attending these meetings that it scared me from continuing them steadily for fear of falling right back to where I had come from, getting high!!

In keeping with the ecological model, here are examples where the person: environment fit. Gitterman and Germain (2008) describe this fit concept as "Favorable or unfavorable fit between the needs, capacities, behavioral styles, and goals of people, and the characteristics of the environment"(p.55). In the above quotes, the fit is unfavorable and as such, respondents did not express positive outcomes in attending meetings, whether it be the perceived inflexibility of the recovery model espoused by AA or the presence of dealers at a meeting created an unhealthy environment that was not conducive to recovery for these respondents.

Another possibility is that this study asked respondents to recall their first year experiences with 12-Step groups. Recovering people may experience higher levels of stress in early recovery versus longer recovery time (Laudet \& White, 2008). This factor 
may have contributed to the present study's results in that respondents' level of stress contributed to the findings. Again, the need for respondents to recall their first year of recovery could have also contributed to the findings in this study, biasing the results.

\section{Social Support}

With foundations in social capital theory and ecological theory, social support can assist a recovering person in maintaining sobriety. As determined in this study, social support, as measured by the Multidimensional Scale of Perceived Social Support, was significantly and positively associated with increased levels of drug abstinence selfefficacy, but not alcohol abstinence self-efficacy. Since 12-Step meetings are a source of social support, the present researcher had concern that multicollinearity would be present between these two independent variables (12-Step meeting and social support) and invalidate the assessment of their independent relationships to with the dependent variables. However, multicollinearity was not present and social support was not significantly related to alcohol abstinence self-efficacy. Again, the dissimilar findings between drug abstinence self-efficacy and alcohol abstinence self-efficacy for this domain are interesting. As with 12-Step meetings, possible first-year recovery stressors could have contributed to negative vicarious experiences and negatively influenced recovery. Similar confounding findings with social support have been reported in other studies.

The study by Laudet and White (2008) also revealed interesting findings about social support. As previously noted, the researchers devised a social support model that dichotomized social support into "general support' (measured by the Social Support 
Appraisal Scale) and "recovery support" (measured by the Social Support Recovery

Scale) for a cohort of inpatient clients whose primary drugs were crack cocaine and heroin. Their findings indicated that only general support and not recovery support was a statistically significant predictor of alcohol abstinence. They questioned why recovery support was not a significant predictor. Just as perplexing is the finding in the present study that social support was not a statistically significant predictor for alcohol abstinence self-efficacy. Further examination of social support for both alcohol and drug abstinence self-efficacy will be pursued in follow-up studies.

The findings from the open-ended questions also reflect the significance social support. One respondent stated that Alcoholics Anonymous provided a healthy environment that promoted recovery:

Having a place where I belonged, with people that had been where I was at the time and I saw that they had gotten better. They gave me health, help, healing and hope. They helped me to develop sanity, stability, security and serenity.

The quote from this respondent highlights the role that Alcoholics Anonymous can play in providing social support while keeping a person active in his or her recovery. Again, the ecological model provides insight into these situations where the meeting provided positive social support and positive exchanges and therefore offered a favorable person:environment fit. 


\section{Financial Status}

Financial status (physical capital predictor) was a not a statistically significant predictor for self-efficacy in either group. Prior studies (Dennis, 2007) had measured physical capital more directly by measuring income. The category used in this study was developed to determine overall financial health using a proxy variable, living environment, for financial stability. The financial capital proxy variables were used (rather than actual income categories) to limit the intrusiveness of the measure. However, the scale developed may not have been sensitive enough to capture the recovery capital domain. Future research should use a more direct measure for financial stability (e.g., salary, financial resources). Such a methodology would mirror other literature on physical capital (Cloud \& Granfield, 2008, Best \& Laudet, 2010).

Interestingly, any themes about physical capital reflected on the lack of resources, which were obstacles to the respondents' recovery.

I called a residential and mental health crisis program ( $\mathrm{sic}$ ) at one time to try to get in for 24-hour monitoring. .... I [was] denied services as a result of no insurance.

At that time 20 plus years ago, there were no facilities in East Texas for women. I relocated to Irving Texas and I was there when I started my recovery. I tried to get in a program, but when the Doctor examined me, he told me they kept the available beds for men ( $\mathrm{sic}$ ) from the Court system that the Judge placed . . . 
From these quotes, the need for physical capital in the form of insurance and a place to receive treatment were lacking and prevented people from receiving the care that they needed.

\section{Treatment Completion and Recovery Capital}

Completion of treatment for the alcohol abstinence cohort (Hypothesis 3 ) and the drug abstinence cohort (Hypothesis 4) did not affect self-efficacy scores. The analysis revealed that for the alcohol abstinence group, the interaction of treatment was not statistically significant. Likewise, for the drug abstinence group, the interaction was not statistically significant. Of the participants enrolled in this study, 183 endorsed attending either outpatient or residential/inpatient treatment. Of these 106 stated that they completed the treatment during that first year of recovery. Thus, while $40 \%$ of participants in the study completed treatment, this factor did not significantly affect the recovery capital effect on the level of self-efficacy. This finding is inconsistent with other studies showing that treatment does play a role in recovery (SAMHSA Treatment Episode Data Set, 2007). This finding may be due to the low number of respondents who endorsed completing treatment $(n=106)$. As a result, the smaller sample size did not provide the statistical power to adequately measure the relationship between treatment completion, recovery capital, and substance use efficacy. 


\section{Future Research and Implications for Social Work}

This study and others that investigate successful recovery from a substance use disorder indicate that recovery capital plays a role in recovery. Future research will further investigate the role that recovery capital in treatment. The findings from this study regarding the interaction of recovery capital and treatment and its effects on drug and alcohol abstinence were disappointing and unexpected given the documented positive role that treatment plays in recovery. Again, one of the reasons for the unexpected results is most likely due, in part, to the small sample of respondents answering the question on treatment completion. As previously discussed, a more robust and thorough examination of the role treatment plays in recovery will be performed. In addition, the role of medication in addiction treatment and effect on recovery success will also be explored. With this said, social work practice should continue to evolve and the findings of this study point to a need to expand the work and education of social workers.

Since recovery capital is so important for the recovery process, social work should take the lead in incorporating the concept of recovery capital and its domains in the treatment arena. Since the beginnings of the profession, social work has promoted the value of social support, whether that be in the form of Jane Addams providing assistance to people at Hull House or in the form of Jesse Taft supporting her clients through a therapeutic relationship. Likewise, social work must continue to view a person within his or her environment. A person's environment cannot be separated from the person. While a recovering person must understand and accept that he or she has an illness, so should social workers be aware of the significant impact that the 
environment can play in recovery efforts. Given this understanding through the lens of recovery capital, social workers should emphasize the importance of a positive recovery environment when providing clinical services to recovering clients.

With the growing evidence that 12-step attendance/affiliation is effective in meeting the recovery needs of the clients we serve, social workers should incorporate Twelve-Step philosophy into standard treatment practice. Twelve-step facilitated treatment is an evidence-based means to accomplish this goal. As previously discussed, twelve-step facilitated treatment has been shown to be effective in facilitating recovery and promoting abstinence (Babor \& Del Boca, 2003; Ouimette, Finney \& Moos, 1997; Sheehan, 2004). Group work in either outpatient or residential treatment would provide an excellent method of engaging clients in 12-Step work. Research has shown that when clients attended treatment groups designed to educate them on the AA experience such as spirituality, sponsorship, and myths about AA, their alcohol and drug abstinence rates were higher than those receiving traditional TSF (Kaskutas, Subbaraman, Witbrodt, \& Zemore, 2009). Such groups should be designed to specifically attend to the domains of recovery capital such as social support and spirituality. This, however, is not an easy task.

Often, those providing treatment for substance use are they themselves in stable recovery from substance dependence (as was the case in the Kaskutas, 2009 study) and are, therefore, often well educated on the merits of 12-Step recovery. They bring personal experience that recovery through the 12 Steps is possible. People suffering from substance use disorders often express concern that their clinicians do not understand addiction and recovery. One of the respondents in this study in commenting 
on what he or she did not like about treatment stated, "Having someone who isn't an addict/alcoholic counseling me. They didn't have a clue." Therefore, social workers who do not have an understanding of addiction and recovery and want to work with clients with substance use disorders should be trained in twelve-step facilitation methods. Social work schools should offer specific courses on 12-Step philosophy and the integration of that philosophy into treatment methods. Twelve-step facilitated treatment is an evidence-based practice and should be taught as such at social work schools with the same fervor as other evidence-based practices such as motivational interviewing and cognitive behavioral treatment.

From this education, social workers would have the insight and, therefore, a responsibility to bring recovery capital and its domains into the treatment environment. Included in this 12-Step treatment is the use of spirituality. As shown in this study and others, spirituality is an important factor in sustaining a person's recovery; helping clients to develop and use this internal resource is key. While, as noted, social support has been an integral part of the profession, spirituality has not been embraced as readily (Bullis, 1996, 2013). However, scholarship has challenged this paradigm and promotes the incorporation of spirituality as an important part of social work practice (Bullis, 1996, 2013; Crisp, 2010). Seinfeld (2012) traces the history of the use of spirituality in social work practice and makes suggestions to integrate spirituality into social work practice:

It is important to utilize the repertoire of spiritual practices within an overall framework of clinical assessment. One basic spiritual practice is encouraging the client to draw up a daily gratitude list. This activity can be useful for those 
individuals experiencing a sense of hopelessness for reasons ranging from suffering loss, depression or deprivation (p. 243).

This idea of incorporating a "daily gratitude list" is central theme in AA and AA literature (Alcoholics Anonymous World Services, Inc. 2001). Key elements of spirituality, so important to AA's success, can easily be incorporated into social work practice.

An important task in any clinical social work practice is the assessment of client functioning. Since a client's success in recovery relates to having recovery capital, social workers should consider assessing a client's level of recovery capital. As mentioned earlier, Groshcova, Best and White (2012), have developed an empirically validated tool to assess recovery capital. The tool assesses similar domains of recovery capital as discussed here while expanding in other domains including "meaningful activities" and "risk taking." Research should be performed to further validate this tool and use it or a similar tool to appropriately assess clients presenting with substance use disorders. From such an assessment, recovery capital focused treatment planning could be developed to help a client build on his/her strengths and develop those recovery capital domains that are weak or missing.

As with any assessment, the results of the recovery capital assessment would be shared with the client and meaningful, client-centered recovery planning could be developed. For example, a client who scores low on spirituality could attend to a group specifically designed to build and strengthen spirituality. In addition, groups could be designed to explore communal experiences of spirituality and members of the group could learn from each other's spiritual experiences, making spirituality a shared 
experience. Likewise, clients having physical capital needs such as inadequate income could attend specific groups to address employment readiness. In such cases, the groups the clients are attending are clinically linked to specific recovery needs and therefore may be more salient with increased motivation and investment in the process.

Finally, further research should be pursued to better understand the relationship between treatment and recovery capital. While the results of this study did not support a statistically significant interaction between recovery capital, treatment completion, and self-efficacy, the number of participants failing to respond to the questions regarding completion of treatment reduced the power of this analysis and this may have skewed the results. As discussed in this chapter, the concept of recovery capital and its domains can easily be adapted for use in treatment. Further, as treatment in substance use disorders continues to expand with the important use of psychopharmacological agents such as Buprenorphine and Methadone, research in the relationship between such medical interventions and recovery capital should be encouraged. Social work should continue to examine the present trends in the treatment of substance use disorders as we continue to learn more about the complicated nature of addiction and recovery. 


\section{References}

Addams, Jane. (1961). Twenty years at Hull-House. New York: Signet Classics.

Alcoholics Anonymous: The Story of How Many Thousands of Men and Women Have Recovered from Alcoholism (2001). (4th Ed.). New York City: Alcoholics Anonymous World Services.

Alcoholics Anonymous. (1981). Twelve steps and twelve traditions. New York: Alcoholics Anonymous World Services.

Allport, G. \& Ross, M. (1967). Personal religious orientation and prejudice. Journal of Personality and Social Psychology, 2 (4), 432-443.

American Psychiatric Association \& American Psychiatric Association. Task Force on DSM-IV. (2000). Diagnostic and statistical manual of mental disorders: DSM-IV-TR (4th, text revision 2000 ed.). Washington, DC: American Psychiatric Association.

Annis, H. (1985). Inventory of drinking situations. In Letter, D, Nelson, J \& Sayers, M. (Eds), Alcoholism Treatment Assessment Research Instruments (pp.32-35). Washington DC: National Institute of Alcohol Abuse and Alcoholism.

Babor, T., \& Del Boca, F. (2003). Treatment matching in alcoholism. Cambridge, UK; New York: Cambridge University Press.

Babor, T.; Steinberg,K.; Zweben, A; Cisler, R; Stout, R.; Tonigan, J.S.; Anton, R. \& Allen, J. (2003). Treatment effects across multiple dimensions of outcome. In Babor, T. \& Del Boca, F. (Eds), Treatment Matching in Alcoholism (pp. 150-165). Cambridge: Cambridge University Press 
Bandura, A. (1977). Self-efficacy: Toward a unifying theory of behavioral change. Psychological Review, 84 (2). 191-215.

Bandura, A. (1989). Human agency in social cognitive theory. American Psychologist, 44 (9), 1175-1184.

Bandura, A. \& Cervone, D. (1983). Self-evaluative and self-efficacy mechanisms governing the motivational effects of goal systems. Journal of Personality and Social Psychology, 45 (5), 1017-1028.

Beauvais, F., \& Oetting, E. R. (1999). Drug use, resilience, and the myth of the golden child. In M. D. Glantz \& J. L. Johnson (Eds.). Resilience and development: Positive life adaptations. New York: Kluwer Academic/Plenum Publishers.

Bliss, D. L. (2008). Empirical research on spirituality and alcoholism: A review of the literature: The reprint. Journal of Social Work Practice in the Addictions, 7(4), 5-25.

Bourdieu, P. (1986). The forms of capital. In Handbook of Theory and Research for the Sociology of Education, Richardson, J.G. pp. 241.58. New York: Greenwood

Brome D.R.; Owens, M.; Allen, K \& Vevaina, T (2008). An examination of spirituality among African-American women in recovery from substance abuse. Journal of Black Psychology 2000 26: 470

Bufford, R.K., Paloutzian, R.F., \& Ellison, C.W. (1982). Norms for the spiritual wellbeing scale. Journal of Psychology and Theology, 19 (1), 56-70.

Bullis, R. $(1996,2013)$. Spirituality in Social Work Practice. Washington DC: Taylor \& Francis 
Bureau of Labor Statistics (2010). Retrieved from http://www.bls.gov/oco/ocos060.htm.

Campbell, A. (1981) The Sense of Well-Being in America: Recent Patterns and Trends. New York: McGraw- Hill

Carroll, M. M. (1997). Spirituality, alcoholism, and recovery: An exploratory study. Alcoholism Treatment Quarterly, 15(4), 89-100.

Cohen, J. (1992). A power primer. Psychological Bulletin, 112(1), 155-159.

Cohen, S. \& Syme, S.L. (1985). Issues in the study and application of social support. In Cohen S. \& Syme, S.L. (Eds.), Social support and health. Orlando, FL: Academic.

Coleman, J. S. (1988). Social capital in the creation of human capital. The American Journal of Sociology, 94 (Supplement: Organizations and Institutions: Sociological and Economic Approaches to the Analysis of Social Structure), pp. S95-S120.

Cloud, R. N., Rowan, N., Wulff, D., \& Golder, S. (2008). Posttreatment 12-step program affiliation and dropout: Theoretical model and qualitative exploration. Journal of Social Work Practice in the Addictions, 7(4), 49.

Cloud, W., \& Granfield, R. (2001). Natural recovery from substance dependency: Lessons for treatment providers. Journal of Social Work Practice in the Addictions, 1(1), 83-104.

Cloud, W., Granfield, R. (2004). The social process of exiting addiction: A life course perspective. Nordic Studies on Alcohol and Drugs, 44:185-202. 
Cloud, W., \& Granfield, R. (2008). Conceptualizing recovery capital: Expansion of a theoretical construct. Substance use \& Misuse, 43(12), 1971-1986.

Cohen, J. (1992). A power primer. Psychological Bulletin, 112(1), 155-159.

Cohen, S., Kamarck, T. \& Mermelstein, R. (1983). A global measure of perceived stress. Journal of Health and Social Behavior, 24(4).

Cohen, S. \& Syme, L. (1985). Social Support and Health. San Francisco: Academic Press.

Connors, G., Maisto, S. \& Zywiak, W. (1996). Understanding relapse in the broader context of post-treatment functioning. Addiction, 91 (12s1), 173-190.

Connors, G. J., Miller, W. R., \& Tonigan, J. S. (2001). A longitudinal model of intake symptomatology, AA participation and outcome: retrospective study of the Project MATCH outpatient and aftercare samples. Journal of Studies on Alcohol, 62(6), 817

Crisp, B. (2010). Spirituality and Social Work. Burlington, VT: Ashgate Publishing Company.

Dennis, M., Foss, M., \& Scott, C, (2007). An eight-year perspective on the relationship between the duration of abstinence and other aspects of recovery. Evaluation Review, 6, 585-612.

DiClemente, C., Carbonari, J., Rosario, P.G., Montgomery, M.A., Hughes, S. (1994). The alcohol abstinence self-efficacy scale. Journal of Studies on Alcohol, 55, 141148. 
Dillman, D. A., Smyth, J.D \& Christian, L.M. (2009). Internet, mail and mixed-mode surveys: The tailored design method. Hoboken, N.J.: Wiley.

Edwards, G., Gross, M., Keller, M., Moser, J. (1976). A summary of the consensus of the WHO group of investigators on criteria for identifying and classifying disabilities related to alcohol consumption. Journal of Studies on Alcohol, 37(9).

Ellison, C.W. (1983). Spiritual well-being; conceptualization and measurement. Journal of Psychology and Theology, 11 (4), 330-340.

Explore the form (2010). Retrieved from http://2010.census.gov/2010census/how/interactive-form.php.

Home | Faces \& Voices of Recovery. (n.d.). Retrieved March 1, 2015, from http://www.facesandvoicesofrecovery.org

Garmezy, N. (1970). Process and reactive schizophrenia: Some conceptions and issues. Schizophrenia Bulletin, 2, 30-74.

Gitterman, A. \& Germain. (2008). The Life Model of Social Work Practice. New York: Columbia University Press.

Glaeser, E. L., Laibson, D., \& Sacerdote, B. (2002). An economic approach to social capital. The Economic Journal, 112(483, Features), pp. F437-F458.

Gossop, M., Brown, N., Stewart, D, Marsden, J. (2003). Alcohol use outcomes and heavy drinking at 4-5 years among a treatment sample of drug misusers. Journal of Substance Abuse Treatment, 25 (3), 135-143. 
Gossop, M., Stewart, D., Marsden, J. (2008). Attendance at narcotics anonymous meetings, frequency of attendance and substance use outcomes after residential treatment for drug dependence: a 5-year follow-up study. Addiction, 103 (1), 119125.

Granfield, R., \& Cloud, W. (1999). Coming clean: Overcoming addiction without treatment. New York: New York University Press.

Groshkova, T., Best, D., White, W. (2012. The assessment of recovery capital: properties and psychometrics of a measure of addiction recovery strengths. Drug and Alcohol Review. 32, 187-194.

Hart, C; Ksir, C. \& Ray, O. (2010). Drugs, Society and Human Behavior (13th) New York: McGraw Hill Companies.

Hasin, D; Stinson, F., Ogburn, E., Grant, B. (2009). Prevalence, correlates, disability, and comorbidity of DSM-IV alcohol abuse and dependence in the united states. Archives of General Psychiatry 64(7), 830-842.

Henderson, N., \& Milstein, M. M. (1996). Resiliency in schools: Making it happen for students and educators. Thousand Oaks, CA: Corwin Press.

Heinz, A. J., Disney, E. R., Epstein, D. H., Glezen, L. A., Clark, P. I., \& Preston, K. L. (2010). A focus-group study on spirituality and substance-user treatment. Substance use \& Misuse, 45(1-2), 134-153.

Hodge, D. R. (2000). Spirituality: Towards a theoretical framework. Social Thought, 19(4), 1-20. 
Hodge, D. R. (2001). Spiritual genograms: A generational approach to assessing spirituality. Families in Society, 82(1), 35-48.

Hodge, D. R. (2003). The intrinsic spirituality scale -- A new six-item instrument for assessing the salience of spirituality as a motivational construct. Journal of Social Service Research, 30(1), 41-61.

Humphreys, K., Kaskutas, L. A., \& Weisner, C. (1998). The Alcoholics Anonymous affiliation scale: Development, reliability, and norms for diverse treated and untreated populations. Alcoholism: Clinical and Experimental Research, 22(5), 974978.

Hser, Y., Polinsky, M.L., Maglione, M., Anglin, M.D. (1999). Matching clients' needs with drug treatment services. Journal of Substance Abuse Treatment, 16(4), 299-305.

Jellinek, E. M. (1960). The disease concept of alcoholism. New Haven: Hillhouse Press.

Kaskutas, L.A., Ammon, L.N., and Weisner, C. (2004). A naturalistic analysis comparing outcomes of substance abuse treatment programs with different philosophies: Social and clinical model perspectives, International Journal of Self Help and Self Care, 2,111-133.

Kaskutas, Meenakshi, Witbrodt \& Zemore (2009). Effectiveness of making alcoholics anonymous easier: A group format 12-step facilitation approach. Journal of Substance Abuse Treatment, 37(3), 228-239. 
Kelly, J., Myers, M., \& Brown, S. (2002). Do adolescents affiliate with 12-step groups? A multivariate process model of effects. Journal of Studies on Alcohol, 63(3), 293304.

Kessler, R. ;Berglund, P.; Demler, O ; Jin, R.; Merikangas, K.; Walters, E. (2005) Lifetime Prevalence and Age-of-Onset Distributions of DSM-IV Disorders in the National Comorbidity Survey Replication. Archives of General Psychiatry. 2005; 62: 593-602.

Krentzman, A. R. (2008). The evidence base for the effectiveness of alcoholics anonymous: Implications for social work practice. Journal of Social Work Practice in the Addictions, 7(4), 27.

Kurtz, E. (1979). Not God: A History of Alcoholics Anonymous. San Francisco: Harper and Row Publishers, Inc.

Larimer, M. E., Marlatt, G. A., \& Palmer, R. S. (1999). Relapse prevention an overview of Marlatt's cognitive-behavioral model. Alcohol Research \& Health, 23, 151.

Laudet, A. (2005). Exploring the recovery process: Patterns, supports, challenges and future directions. Presented at the Seminar Series of the Division of Epidemiology, Services and Prevention Research (DESPR). National Institute on Drug Abuse (NIDA). Retrieved from: www.ndri.org/ctrs/cstar/laudet0405.ppt.

Laudet, A (2008) The Road to Recovery: Where are we going and how do we get there? Empirically-driven conclusions and future directions for service development and research. Substance Use and Misuse, 43 (12/13), 2001-2020. 
Laudet, A., Magura, S., Vogel, H., \& Knight, E. (2002) Interest in and obstacles to pursuing work among unemployed dually-diagnosed individuals. Substance Use and Misuse, 37(2), 145 -170. PMCID: 1797894

Laudet, A., Savage, R. and Mahmood, D. (2002) Pathways to long-term recovery: A preliminary investigation. Journal of Psychoactive Drugs, 34(3), 305-311.

Laudet, A.B., Magura, S., Cleland, C.M., Vogel, H.S., Knight, E.L., \& Rosenblum, A. (2004). The effect of 12-step based fellowship participation on abstinence among dually-diagnosed persons: A two year longitudinal study. Journal of Psychoactive Drugs, 36, 207-216

Laudet, A.B., Magura, S., Cleland, C.M., Vogel, H.S., Knight, E.L. (2004). Social support mediates the effects of dual-focus mutual aid groups on abstinence from substance use. American Journal of Community Psychology, 34, 175-185.

Laudet, A. B., Morgen, K., \& White, W. L. (2006). The role of social supports, spirituality, religiousness, life meaning and affiliation with 12-step fellowships in quality of life satisfaction among individuals in recovery from alcohol and drug problems. Alcoholism Treatment Quarterly, 24(1-2), 33-73.

Laudet, A. B., \& White, W. L. (2008). Recovery capital as prospective predictor of sustained recovery, life satisfaction, and stress among former poly-substance users. Substance use \& Misuse, 43(1), 27-54. 
Laudet, A. B., \& Stanick, V. (2010). Predictors of motivation for abstinence at the end of outpatient substance abuse treatment. Journal of Substance Abuse Treatment, 38(4), 317-327.

Lowman, C., \& Allen, J. (1996). Replication and extension of Marlatt's taxonomy of relapse precipitants: Overview of procedures and results. Addiction, 91, S51-S71

Luthar, S. S., \& Cicchetti, D. (2000). The construct of resilience: A critical evaluation and guidelines for future work. Child Development, 71(3), 543.

Marlatt, GA \& Donovan, D $(1985,2007)$. Relapse Prevention: Maintenance Strategies in the Treatment of Addictive Behaviors. New York: The Guildford Press.

Mancini, M., Linhorst, D., Broderick, F., \& Bayliff, S. (2008). Challenges to implementing the harm reduction approach. Journal of Social Work Practice in the Addictions, 8 (3), 380-408.

Mayfield, D; McLeod, G.; Hall, P. (1974). The cage questionnaire: validation of a new alcoholism screening instrument. American Journal of Psychiatry, 131(9), 11211123.

Meichenbaum, D in Brom, D., Pat-Horenczyk, R. \& Ford, J. (Eds.). (2008). Bolstering resilience: Benefiting from lessons learned Treating traumatized children: Risk, Resilience and Recovery. New York: Routledge.

McConnaughy, E. A., Prochaska, J. O., \& Velicer, W. F. (1983). Stages of change in psychotherapy: Measurement and sample profiles. Psychotherapy: Theory, Research \& Practice, 20(3), 368-375. 
McElrath, K., Chitwood, D, Griffin, D. \& Comford, M. (1994). The consistency of selfreported HIV risk behaviors among injection drug users. American Journal of Public Health, 84(12).

McKellar, J., Stewart, E., \& Humphreys, K. (2003). Alcoholics anonymous involvement and positive alcohol-related outcomes: Cause, consequence, or just a correlate? A prospective 2-year study of 2,319 alcohol-dependent men. Journal of Consulting and Clinical Psychology, 71(2), 302-308.

McLellan, A.T., Lewis, D. C., O'Brien, et al. (2000). Drug dependence, a chronic medical illness: Implications for treatment, insurance, and outcomes evaluation. Journal of the American Medical Association, 284(13), 1689-1695.

Miller, W. R., Tonigan, J. S., \& Connors, G. J. (2000). Project MATCH client impressions about alcoholics anonymous -- measurement issues and relationship to treatment outcome. Alcoholism Treatment Quarterly, 18(1), 25.

Miller, W.; Zweben, A.; DiClemente, C. \& Rychtarik, R. (1992). MotivationalEnhancement Therapy Manual: A Clinical Research Guide for Therapists Treating Individuals with Alcohol Abuse and Dependence, Project MATCH Monograph Series, Vol. 2, NIH Publication No. 94-3723. Rockville, MD: National Institute on Alcohol Abuse and Alcoholism.

Morgenstern, J., Labouvie, E., McCrady, B. S., Kahler, C. W., \& Frey, R. M. (1997). Affiliation with alcoholics anonymous after treatment: A study of its therapeutic effects and mechanisms of action. Journal of Consulting and Clinical Psychology, 65(5), 768-777. 
NA World Services, Inc. (2013). Narcotics Anonymous Membership Survey. Van Nuys, CA: NA World Services, Inc.

Koob, G. \& Volkow, N. (2010). Neurocircuitry of addiction. Neuropsychopharmacology, $35,217-238$.

Nunnally, JC (1978). Psychometric Theory, New York: McGraw-Hill.

Ouimette, P. C., Finney, J. W., \& Moos, R. H. (1997). Twelve-step and cognitive-behavioral treatment for substance abuse: A comparison of treatment effectiveness. Journal of Consulting and Clinical Psychology, 65(2), 230-240.

Paloutzian, R.F., \& Ellison, C.W. Loneliness, spiritual well-being and quality of life In Peplau, L. A., \& Perlman, D. (1982). Loneliness: A sourcebook of current theory, research, and therapy. New York: Wiley.

Pentz, M (2005) Resilience among older adults with cancer and the importance of social support and spirituality-faith, Journal of Gerontological Social Work, 44: 3, 3 -22.

Perlman, H (1957). Social Casework. Chicago: The University of Chicago Press.

Portes, A. (1998). Social capital: Its origins and applications in modern sociology. Annual Review of Sociology, 24, 1-24.

Roberts, A. C., Galassi, J. P., McDonald, K., \& Sachs, S. (2002). Reconceptualizing substance abuse treatment in therapeutic communities: Resiliency theory and the role of social work practitioners. Journal of Social Work Practice in the Addictions, 2(2), 53-68. 
Rahill, G., Lopez, E., Vanderbiest, A., Rice, C. (2009). What is relapse? A contemporary exploration of treatment of alcoholism. Journal of Social Work Practice in the Addictions, 9 (3), 245-262.

Ross, S., \& Peselow, E. (2009). Pharmacotherapy of addictive disorders. Clinical Neuropharmacology, 32(5), 277-289.

Rush, B. (1823). An Inquiry into the Effects of Ardent Spirits Upon the Mind and Body with an Account of the Means of Prevention and of the Remedies for Them. Boston: James Loring.

Seinfeld, J. (2012). Spirituality in social work practice. Clinical Social Work Journal, 40, 240-244.

Sheehan, T. (2004). Twelve step facilitation: A necessary treatment for offenders. Journal of Forensic Practice, 4(3), 71-81

Stewart, S., Barton Samoluk, S., Conrad, P., Pihl, R., Dongier, M. (2000\}. Psychometric evaluation of the short form inventory of drinking situations (IDS-42) in a community-recruited sample of substance abusing women. Journal of Substance Abuse, 11 (3), 305-321.

Taft, J. (1946). Counseling and Protective Service As Family Case Work: A Functional Approach. Philadelphia: University of Pennsylvania.

Tonigan, J. S., Connors, G. J., \& Miller, W. R. (1996). Alcoholics anonymous involvement (AAI) scale: Reliability and norms. Psychology of Addictive Behaviors, 10(2), 75-80. 
United Nations, Office on Drugs and Crime. (2008). Drug dependence treatment: Sustained recovery management. Retrieved from www. unodc. org/...l

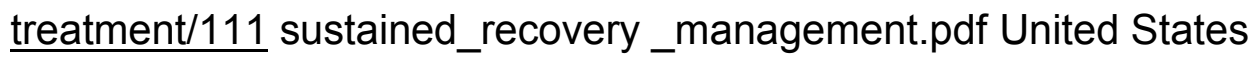

United States Census Bureau (2010). American community survey. Retrieved from http://www.census.gov/acs/www/about the survey/american community survey a nd 2010 census/.

United States Department of Health and Human Services, US Public Health Service (1999). Mental Health: A report of the Surgeon General. Retrieved from http://www.surgeongeneral.gov/library/mentalhealth/pdfs/front.pdf.

United. States Department of Health and Human Services SAMHSA, Office of Applied Studies (2010). National survey on drug use and health. Retrieved from http://www.oas.samhsa.gov/nhsda.htm.

United States Department of Health and Human Services SAMHSA Treatment episode data set (TEDS): 2005. Retrieved from http://wwwdasis.samhsa.gov/teds05/TEDSD2k5TOC.htm\#figures

Valliant, G. \& Milofsky, E. (1982). Natural history of male alcoholism iv. paths to recovery. Archives of General Psychiatry, 39(2), 127-133.

Weisner, C., Thomas Ray, G., Mertens, J. R., Satre, D. D., \& Moore, C. (2003). Shortterm alcohol and drug treatment outcomes predict long-term outcome. Drug and Alcohol Dependence, 71(3), 281-294. 
White, W. (1998). Slaying the dragon: The history of addiction treatment and recovery in america. Bloomington, IL: Chestnut Health Systems/Lighthouse Institute.

White, W. \& Cloud, W. (2008). Recovery capital: A primer for addictions professionals. Counselor, 9(5), 22-27.

Wolf, S., Patterson, D. A., \& Nochaski, T. H. (2008). Combining the transtheoretical stages of change model and the 12 steps of alcoholics anonymous to monitor treatment progression. Journal of Social Work Practice in the Addictions, 10(2)

Wong, J. (2006). Social support: A key to positive parenting outcomes for mothers in residential drug treatment with their children. Journal of Social Work Practice in the Addictions, 6(1-2), 113-137.

World Health Organization (2004). Management of substance abuse facts and figures. Retrieved from http://www.who.int/substance_abuse/facts/en/.

Zigler, E., \& Glick, M. (1986). A Developmental Approach to Adult Psychopathology. New York: Wiley.

Zimet, G. D., Dahlem, N. W., Zimet, S. G., \& Farley, G. K. (1988). The multidimensional scale of perceived social support. Journal of Personality Assessment, 52(1), 30. 
Figure 1: Hypothesized Effect of Recovery Capital on Alcohol and Drug Abstinence Self-Efficacy

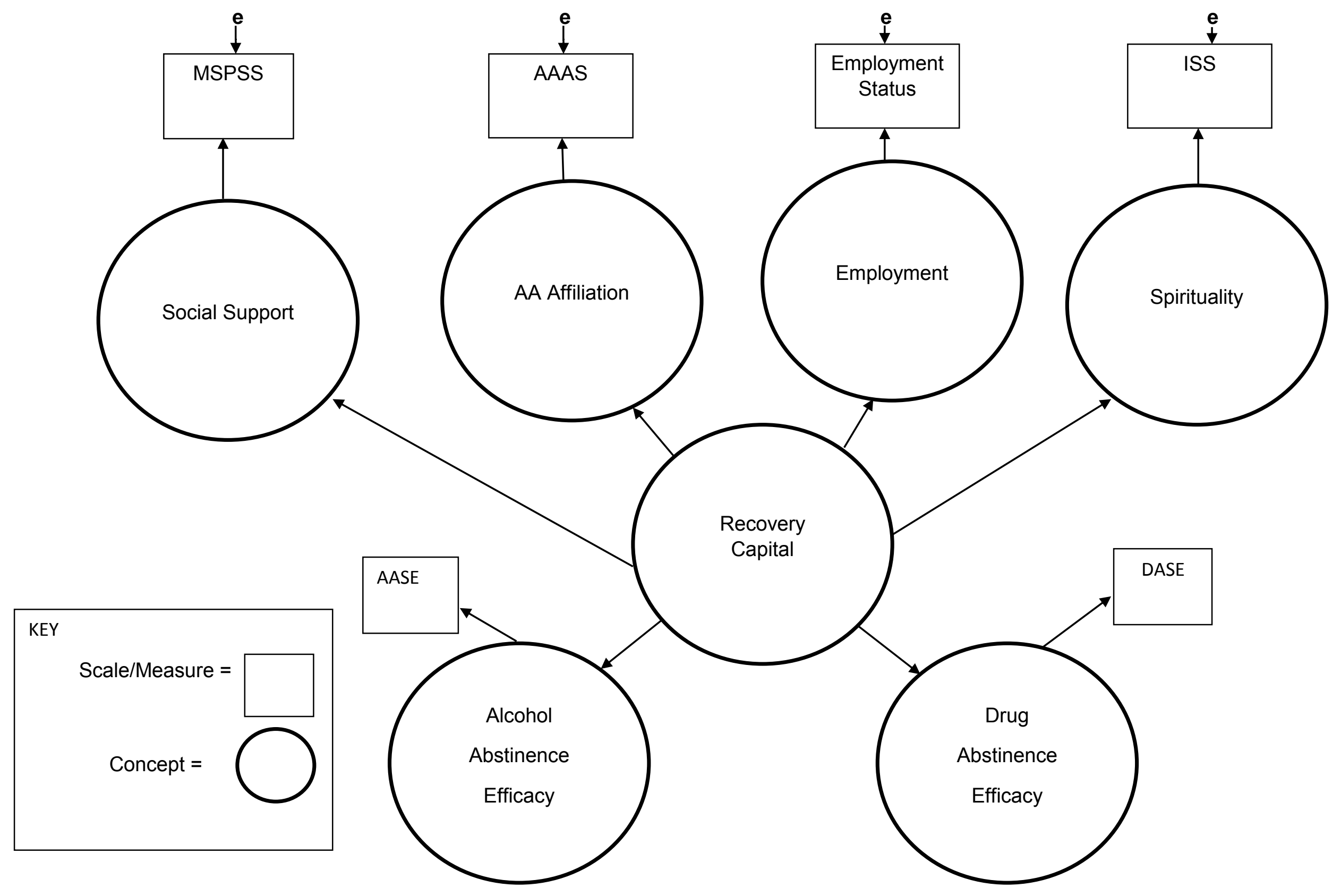


Figure 2: Hypothesized Moderating Effects of Treatment

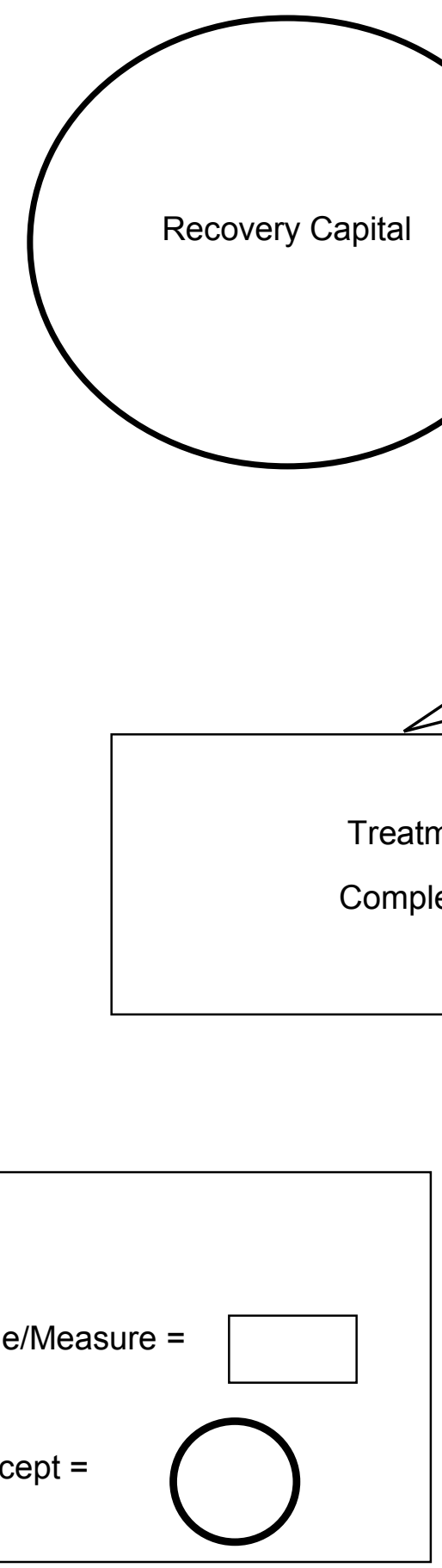

Drug Abstinence Efficacy (DV) 
Appendix A: Study Survey

Recovery Capital

Q1 Thank you for your willingness to participate in this study that will investigate the process of recovery from alcoholism and drug addiction. This study is being done to help the researchers gain insight into the reasons why people are able to recover. You are going to be asked to fill out an online survey with a variety of questions related to use of alcohol and drugs and your recovery process. The survey should take no longer than 10 to 15 minutes to complete. Besides the time this will take to fill out, we anticipate no inconveniences. The level of risk involved in participating in this study is considered minimal. However, recalling past substance use may create uncomfortable thoughts and feelings. If you experience any discomfort, you may skip any or all questions. Through the data collected, the researchers hope to gain new information regarding the recovery process. This information could then be used to inform treatment providers and other addiction professionals on improved ways to assist clients in recovery. There are no costs for you to participate. All of your responses to the survey will be kept confidential and anonymous. Five years after the study is complete, all data will be destroyed. You will not receive payment for participation; however, as a token of appreciation for completing the study, you can enter into a drawing to win a 25.00 gift card to Starbucks. A link will be provided at the end of this survey which will allow you to enter into the drawing by providing your email address. No information entered for the survey will be linked to your email address. The drawing will take place at the conclusion of the survey collection with one person selected to win the gird card. We will contact the winner via the email address provided and request an address to which to send the card. You should also know that the UCONN Institutional Review Board (IRB) and the Office of Research Compliance may inspect study records as part of its auditing program, but these reviews will only focus on the researchers and not on your responses or involvement. The IRB is a group of people who review research studies to protect the rights and welfare of research participants. We will be happy to answer any question you have about this study. If you have further questions about this project, or if you have a research-related problem, you may contact the principal investigator Brenda Kurz at (860) 570-9153.or the student researcher, William Gilbert at (860) 331-3351. If you have any questions concerning your rights as a research subject, you may contact the 
University of Connecticut Institutional Review Board (IRB) at 860-486-8802 I understand the above and agree to participate in this survey.

O No

O Yes

Q1 Are you able to read and write in English?

O No

O Yes

Q2 How old are you now?

O 17 or younger

O $18-30$

O $31-44$

O $45-59$

O 60-74

O 75 or older

Q3 What is the highest level of of education you have completed?

L Less than eighth grade

O Junior high school/Middle school or less

O High school

O Some college

O College or beyond

Q4 What is your gender?

O Male

O Female 
Q5 What race do you consider yourself to be? Check all that apply

White

Asian

A African-American or Black

- Native-American/American Indian or Alaska Native

- Native Hawaiian /Pacific Islander

$\square$ Other

ㄱot Known

Q5a Are you Spanish/Hispanic/Latino?

$\mathrm{O}$ Yes

O No

Q6 What best describes your current relationship status (CHECK ONE)

O Single, Never Married

O Married or Civil Union

O Widowed

O Divorced

O Separated

O Committed romantic partner

Q7 Are you currently employed?

O Yes

O No

Q8 Please check any of the following that apply:

O I am retired

O Out of work and currently looking for work

O Out of work and not currently looking for work

O I am a homemaker

O I am a student

O I am in the military

O Unable to work due to a disability 
Q9 No matter what the source of income, about how much money did you earn or receive last year?

O Under $\$ 25,000$

O $\$ 25,000-\$ 50,000$

O Over $\$ 50,000$ but under $\$ 100,000$

O 100,000 or more

Q10 For you household as a whole, about how much money did your household earn or receive last year no matter what the source of income?

O Under $\$ 25,000$

O $\$ 25,000-\$ 50,000$

O Over $\$ 50,000$ but under $\$ 100,000$

O 100,000 or more

Q11 To understand the process of recovery from different substances, the following questions will address your personal history, including your alcohol and drug use. Your answers will be kept completely confidential.

Q12 Please give your age of first use of the following substances.

\begin{tabular}{|c|c|}
\hline Alcohol & Age of First Use (If never used enter "0") \\
Cocaine (any form) & \\
Marijuana (not prescribed) & \\
Tranquilizers and/or sedatives (not \\
prescribed or not as prescribed or were \\
used for experience or feeling it caused). \\
Opiates (including heroin or pain relievers \\
that were not prescribed or not as \\
prescribed or were used for experience \\
or feeling it caused). \\
Other (please name below)
\end{tabular}


Q13 Please give the month and year of your last use of the following substances:

\begin{tabular}{|c|c|}
\hline Alcohol & $\begin{array}{c}\text { Approximate month, day, and year } \\
\text { (mm/dd/yyy) of last use (if not sure, } \\
\text { please estimate) }\end{array}$ \\
\hline Cocaine (any form) & \\
Marijuana (not prescribed) & \\
Tranquilizers and/or sedatives (not \\
prescribed or not as prescribed or were \\
used for experience or feeling it caused). \\
$\begin{array}{c}\text { Opiates (including heroin or pain relievers } \\
\text { that were not prescribed or not as } \\
\text { prescribed or were used for experience } \\
\text { or feeling it caused). } \\
\text { Other (please name below) }\end{array}$ \\
\hline
\end{tabular}

Q14 Please click on the substances that you have used in the past six months.

\section{alcohol}

Cocaine (any form)

- Marijuana (not prescribed)

- Tranquilizers and/or sedatives (not prescribed or not as prescribed)

Opiates (including heroin or pain relievers that were not prescribed and were used for experience or feeling it caused).

$\square$ Other (please name below)

Done

Q15 How old were you when you began your recovery? If you have been in recovery more than once, think about your current recovery.

O Under 30

O $30-44$

O $45-59$

O 60-74

O 75 or older 
Q16 How long have you considered yourself in recovery?

Years

Months

Q17 Have you been abstinent from alcohol and all drugs (other than those taken as prescribed by a physician) in that entire time?

$\mathrm{O}$ Yes

O No

Q18 If yes, how long have you been completely abstinent?

Years

Months

Q19 Are you currently abstinent from alcohol and all drugs other than those taken as prescribed?

$\mathrm{O}$ Yes

O No

Q20 Please click on the substances that were a problem for you. Click all that apply.

Alcohol

Cocaine (any form)

Marijuana (not prescribed)

- Tranquilizers and/or sedatives (not prescribed or not as prescribed)

Opiates (including heroin or pain relievers that were not prescribed and were used for experience or feeling it caused).

Other (please name below) 
Q21 Of the drugs that you clicked on in the previous question as a problem, which was your drug of choice?

O Alcohol

O Cocaine (any form)

O Marijuana (not prescribed)

Tranquilizers and/or sedatives (not prescribed)

Opiates (including heroin or pain relievers that were not prescribed and were used for experience or feeling it caused)

Other (please name below)

Q22 The following questions refer to your first year of recovery. Please think back about this period of time, and answer the questions as well as you can. If you have been in recovery more than once, please think back to the first year of THIS recovery period. If your current recovery is less than one year, please think about THIS FIRST YEAR of your current recovery period.

Q23 What best describes your marital or other romantic relationship status during the first year of your recovery? (Check one).

S Single, no partner for most of the time

O Married or in another committed relationship for most of the time

Q24 What best describes your financial situation during the first year of recovery?

O Most of the year, I was broke and homeless, or staying with others

O Most of the year, I struggled to meet my basic needs or the needs of my family

O Most of the year, I was able to meet my needs, but depended on help from others

O Most of the year, I was comfortable enough but had to be very careful with money

O Most of the year, I did not have to worry about money too much

Q25 These next questions deal with treatment for alcohol or drug use during the first year of your recovery. Please think back about this period of time, and answer the questions as well as you can. If you have been in recovery more than once, please think back to the first year of THIS recovery period. If your current recovery is less than one year, please think about THIS FIRST YEAR of your current recovery period. 
Q26 Did you participate in treatment for your substance use disorder?

$\mathrm{O}$ Yes

O No

Q27 During your first year of recovery, were you in any type of inpatient treatment (for example, hospital or residential programs) for alcohol or drug use?

$\mathrm{O}$ Yes

O No

Q28 During your first year of recovery, were you in any type of of outpatient treatment (for example, counseling centers) for alcohol or drug use?

$\mathrm{O}$ Yes

O No

Q29 Altogether, about how much time did you spend in treatment during your first year of recovery? (Do not include time in AA, NA, or other 12-step program here, only formal treatment programs.)

O None

O Less than 3 months

O At least 3 months, but less than 6 months

O At least 6 months, but less than 9 months

O At least 9 months, but less than 12 months

O All 12 months

Q30 When in treatment, did you receive counseling or treatment that included AA, NA or other twelve-step meetings?

$\mathrm{O}$ Yes

O No

Q31 Did you complete any treatment program during your first year of recovery? That is, were you discharged successfully?

O Yes

O No 
Q32 What was most beneficial in the treatment you received?

Q33 What was least beneficial to the treatment your received?

Q34 Why did you not participate in treatment?

Q35 Did you attend AA, NA or other 12-step meetings?

O Yes

O No

Q36 This section asks about your participation in Alcoholics Anonymous, Narcotics Anonymous or other twelve-step meeting during the first year of your recovery. Please think back about this period of time, and answer the questions as well as you can. If you have been in recovery more than once, please think back to the first year of THIS 
recovery period. If your current recovery is less than one year, please think about THIS FIRST YEAR of your current recovery period.

\begin{tabular}{|c|c|c|}
\hline & Yes & No \\
\hline $\begin{array}{c}\text { Did you consider yourself } \\
\text { a member of } A A \text { or NA } \\
\text { during the first year of } \\
\text { recovery? }\end{array}$ & 0 & 0 \\
\hline $\begin{array}{l}\text { During the first year of } \\
\text { recovery, did you ever call } \\
\text { a member of AA or NA? }\end{array}$ & 0 & 0 \\
\hline $\begin{array}{l}\text { During the first year of } \\
\text { recovery, did you have an } \\
\text { AA or NA sponsor? }\end{array}$ & 0 & 0 \\
\hline $\begin{array}{c}\text { During the first year of } \\
\text { recovery, did you ever } \\
\text { sponsor anyone else in AA } \\
\text { or NA? }\end{array}$ & 0 & 0 \\
\hline $\begin{array}{l}\text { During the first year of } \\
\text { recovery, did you have a } \\
\text { spiritual or religious } \\
\text { awakening or a conversion } \\
\text { as a result of your } \\
\text { participation in AA or NA? }\end{array}$ & 0 & 0 \\
\hline $\begin{array}{l}\text { During the first year of } \\
\text { recovery, did you read AA } \\
\text { or NA literature? }\end{array}$ & 0 & 0 \\
\hline $\begin{array}{l}\text { During the first year of } \\
\text { recovery, did you do a } \\
\text { service, (helped } \\
\text { newcomers, or set up } \\
\text { chairs, made coffee, } \\
\text { cleaned up after a } \\
\text { meeting, etc.)? }\end{array}$ & 0 & 0 \\
\hline
\end{tabular}

Q37 What was most helpful about attending AA, NA or other 12-step meetings? 
Q38 What was the least helpful about attending AA, NA or other 12-step meetings?

Q39 Why did you not attend AA, NA or other 12-step meetings?

Q40 Please continue to consider the first year of your recovery as you answer the remainder of this survey. Remember, please think back about this period of time, and answer the questions as well as you can. If you have been in recovery more than once, please think back to the first year of THIS recovery period. If your current recovery is less than one year, please think about THIS FIRST YEAR of your current recovery period.

Q41 For this next section, spirituality is defined as one's relationship to God or whatever you perceive to be as the Ultimate Transcendence or Higher Power. A sentence fragment is provided, followed by a scale ranging from 0 to 10 connected to the phrases above them. Please select the number that best reflects your feeling during the first year of your recovery. As practice for these set of questions, please complete the first item as follows. If today you are feeling "The worst I have felt in years" click on 0 . If you are feeling "The best I have felt in years" click on 10. If you are feeling somewhere in the middle click on a number in between that best reflects how you are feeling.

\begin{tabular}{|c|c|c|c|c|c|c|c|c|c|c|c|}
\hline & 0 & 1 & 2 & 3 & 4 & 5 & 6 & 7 & 8 & 9 & 10 \\
\hline $\begin{array}{c}\text { During } \\
\text { the first } \\
\text { year of } \\
\text { recovery } \\
\text { I felt }\end{array}$ & 0 & 0 & 0 & 0 & 0 & 0 & 0 & 0 & 0 & 0 & 0 \\
\hline
\end{tabular}


Q42

\begin{tabular}{|c|l|l|l|l|l|l|l|l|l|l|l|}
\hline $\begin{array}{c}\text { In terms } \\
\text { of the } \\
\text { questions } \\
\text { I had } \\
\text { about life, } \\
\text { my } \\
\text { spirituality } \\
\text { answered }\end{array}$ & 0 & 0 & 0 & 0 & 0 & 0 & 0 & 0 & 0 & 0 & 0 \\
\hline
\end{tabular}

Q43.

\begin{tabular}{|c|c|c|c|c|c|c|c|c|c|c|c|}
\hline $\begin{array}{c}\text { Growing } \\
\text { spirituality } \\
\text { was }\end{array}$ & 10 & 9 & 8 & 7 & 6 & 5 & 4 & 3 & 2 & 1 & 0 \\
\hline
\end{tabular}

Q44 .

\begin{tabular}{|c|l|l|l|l|l|l|l|l|l|l|l|}
\hline $\begin{array}{c}\text { When I } \\
\text { was } \\
\text { faced } \\
\text { with an } \\
\text { important } \\
\text { decision, } \\
\text { my } \\
\text { spirituality }\end{array}$ & 0 & 0 & 0 & 0 & 0 & 0 & 0 & 0 & 0 & 0 & 0 \\
\hline
\end{tabular}


Q45.

\begin{tabular}{|c|c|c|c|c|c|c|c|c|c|c|c|}
\hline $\begin{array}{c}\text { Spirituality } \\
\text { was }\end{array}$ & 10 & 9 & 8 & 7 & 6 & 5 & 4 & 3 & 2 & 1 & 0 \\
\hline
\end{tabular}

Q46.

\begin{tabular}{|c|l|l|l|l|l|l|l|l|l|l|l|}
\hline & 0 & 1 & 2 & 3 & 4 & 5 & 6 & 7 & 8 & 9 & 10 \\
\hline $\begin{array}{c}\text { When I } \\
\text { think of } \\
\text { the things } \\
\text { that } \\
\text { helped } \\
\text { me grow } \\
\text { and } \\
\text { mature as } \\
\text { a person, } \\
\text { my } \\
\text { spirituality }\end{array}$ & 0 & 0 & 0 & 0 & 0 & 0 & 0 & 0 & 0 & 0 & 0 \\
\hline
\end{tabular}

Q47.

\begin{tabular}{|c|c|c|c|c|c|c|c|c|c|c|c|}
\hline & 10 & 9 & 8 & 7 & 6 & 5 & 4 & 3 & 2 & 1 & 0 \\
\hline $\begin{array}{c}\text { My } \\
\text { spiritual } \\
\text { beliefs } \\
\text { affected }\end{array}$ & 0 & 0 & 0 & 0 & 0 & 0 & 0 & 0 & 0 & 0 & 0 \\
\hline
\end{tabular}


Q48 The following questions are designed to measure the support in your life. For each item, please click on the number that corresponds to how you felt during the first year of recovery. 


\begin{tabular}{|c|c|c|c|c|c|c|c|}
\hline & $\begin{array}{c}\text { Very } \\
\text { Strongly } \\
\text { Disagree } \\
1\end{array}$ & $\begin{array}{c}\text { Strongly } \\
\text { Disagree } \\
2\end{array}$ & $\begin{array}{c}\text { Mildly } \\
\text { Disagree } \\
3\end{array}$ & $\begin{array}{c}\text { Neutral } \\
4\end{array}$ & $\begin{array}{l}\text { Mildly } \\
\text { Agree } \\
5\end{array}$ & $\begin{array}{l}\text { Strongly } \\
\text { Agree } 6\end{array}$ & $\begin{array}{c}\text { Very } \\
\text { Strongly } \\
\text { Agree } 7\end{array}$ \\
\hline $\begin{array}{c}\text { There } \\
\text { was a } \\
\text { special } \\
\text { person } \\
\text { who was } \\
\text { around } \\
\text { when I } \\
\text { was in } \\
\text { need. }\end{array}$ & 0 & 0 & 0 & 0 & 0 & 0 & 0 \\
\hline $\begin{array}{c}\text { There } \\
\text { was a } \\
\text { special } \\
\text { person in } \\
\text { my life } \\
\text { with } \\
\text { whom I } \\
\text { could } \\
\text { share } \\
\text { joys and } \\
\text { sorrows. }\end{array}$ & 0 & 0 & 0 & 0 & 0 & 0 & 0 \\
\hline $\begin{array}{c}\text { My family } \\
\text { really } \\
\text { tried to } \\
\text { help me. }\end{array}$ & O & 0 & 0 & 0 & 0 & 0 & 0 \\
\hline $\begin{array}{l}\text { I got the } \\
\text { emotiona } \\
\text { support I } \\
\text { needed } \\
\text { from my } \\
\text { family. }\end{array}$ & O & 0 & O & 0 & 0 & 0 & 0 \\
\hline $\begin{array}{l}\text { I had a } \\
\text { special } \\
\text { person } \\
\text { who was } \\
\text { a real } \\
\text { source of } \\
\text { comfort } \\
\text { to me. }\end{array}$ & 0 & 0 & 0 & 0 & 0 & 0 & 0 \\
\hline
\end{tabular}




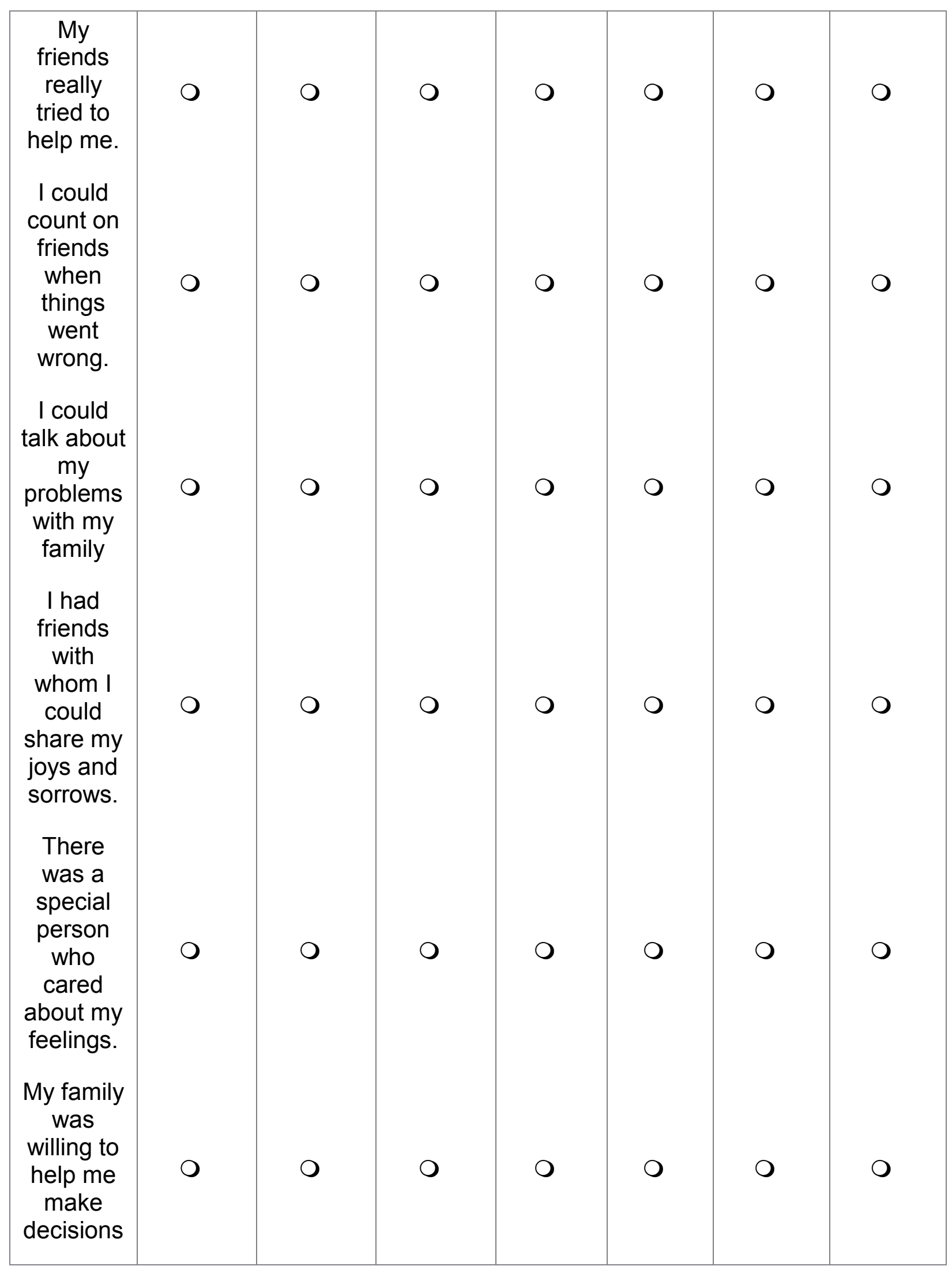




\begin{tabular}{|c|c|c|c|c|c|c|c|}
\hline $\begin{array}{l}\text { I could } \\
\text { talk about } \\
\text { my } \\
\text { problems } \\
\text { with my } \\
\text { friends. }\end{array}$ & 0 & 0 & 0 & 0 & 0 & 0 & 0 \\
\hline
\end{tabular}

Q49 Do you identify as being in recovery from drug addiction to illegal drugs?
$\mathrm{O}$ Yes
O No

Q50 Listed below are a number of situations that lead some people to use illegal drugs. Please think back to the end of your first year of recovery. We would like to know how confident you were that you would not use illegal drugs in each situation about one year after your recovery began. For each situation (items to the left), select the number that best describes the extent to which you were confident you would not use illegal drugs. If the situation is not applicable to you click on "Not applicable to me." $1=$ not 
at all confident $2=$ not very confident $3=$ moderately confident $4=$ very confident $5=$ extremely confident $6=$ not applicable to me 


\begin{tabular}{|c|c|c|c|c|c|c|}
\hline & $\begin{array}{l}\text { not at all } \\
\text { confident }\end{array}$ & $\begin{array}{l}\text { not very } \\
\text { confident }\end{array}$ & $\begin{array}{c}\text { moderately } \\
\text { confident }\end{array}$ & $\begin{array}{c}\text { very } \\
\text { confident }\end{array}$ & $\begin{array}{l}\text { extremely } \\
\text { confident }\end{array}$ & $\begin{array}{c}\text { not } \\
\text { applicable } \\
\text { to me }\end{array}$ \\
\hline $\begin{array}{l}\text { When I was } \\
\text { in agony } \\
\text { because of } \\
\text { stopping or } \\
\text { withdrawing } \\
\text { from drug } \\
\text { use. }\end{array}$ & 0 & 0 & 0 & 0 & 0 & 0 \\
\hline $\begin{array}{l}\text { When I had } \\
\text { a headache. }\end{array}$ & 0 & 0 & 0 & 0 & O & 0 \\
\hline $\begin{array}{l}\text { When I was } \\
\text { feeling } \\
\text { depressed. }\end{array}$ & 0 & 0 & 0 & 0 & 0 & 0 \\
\hline $\begin{array}{c}\text { When I was } \\
\text { on vacation } \\
\text { and wanted } \\
\text { to relax. }\end{array}$ & 0 & 0 & 0 & 0 & 0 & 0 \\
\hline $\begin{array}{l}\text { When I was } \\
\text { concerned } \\
\text { about } \\
\text { someone. }\end{array}$ & O & 0 & 0 & 0 & 0 & 0 \\
\hline $\begin{array}{l}\text { When I was } \\
\text { worried. }\end{array}$ & $O$ & 0 & 0 & 0 & 0 & 0 \\
\hline $\begin{array}{l}\text { When I had } \\
\text { the urge to } \\
\text { use drugs to } \\
\text { see what } \\
\text { happens. }\end{array}$ & 0 & 0 & 0 & O & 0 & 0 \\
\hline $\begin{array}{l}\text { When I was } \\
\text { offered } \\
\text { drugs in a } \\
\text { social } \\
\text { situation. }\end{array}$ & 0 & 0 & 0 & 0 & 0 & 0 \\
\hline
\end{tabular}




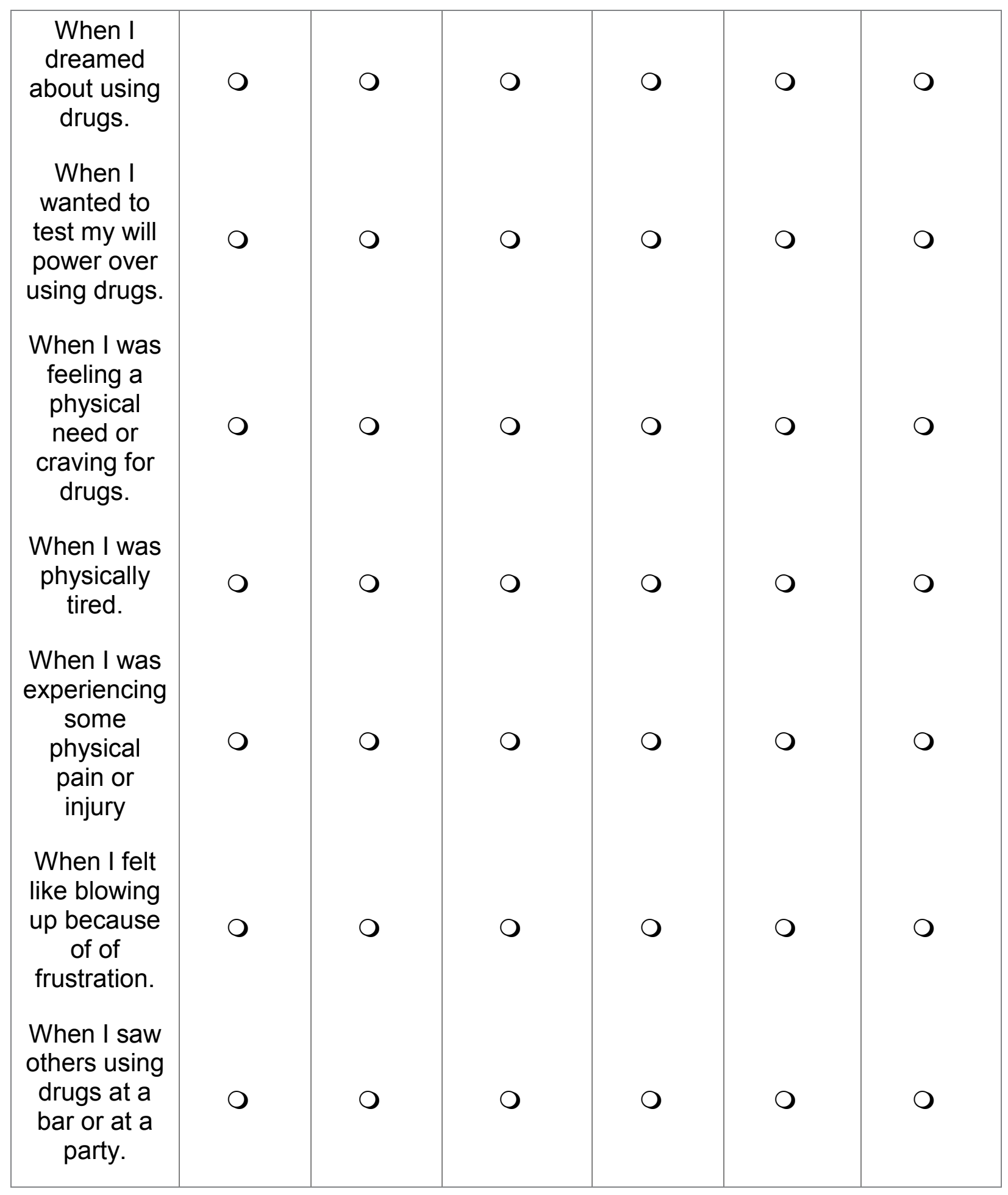




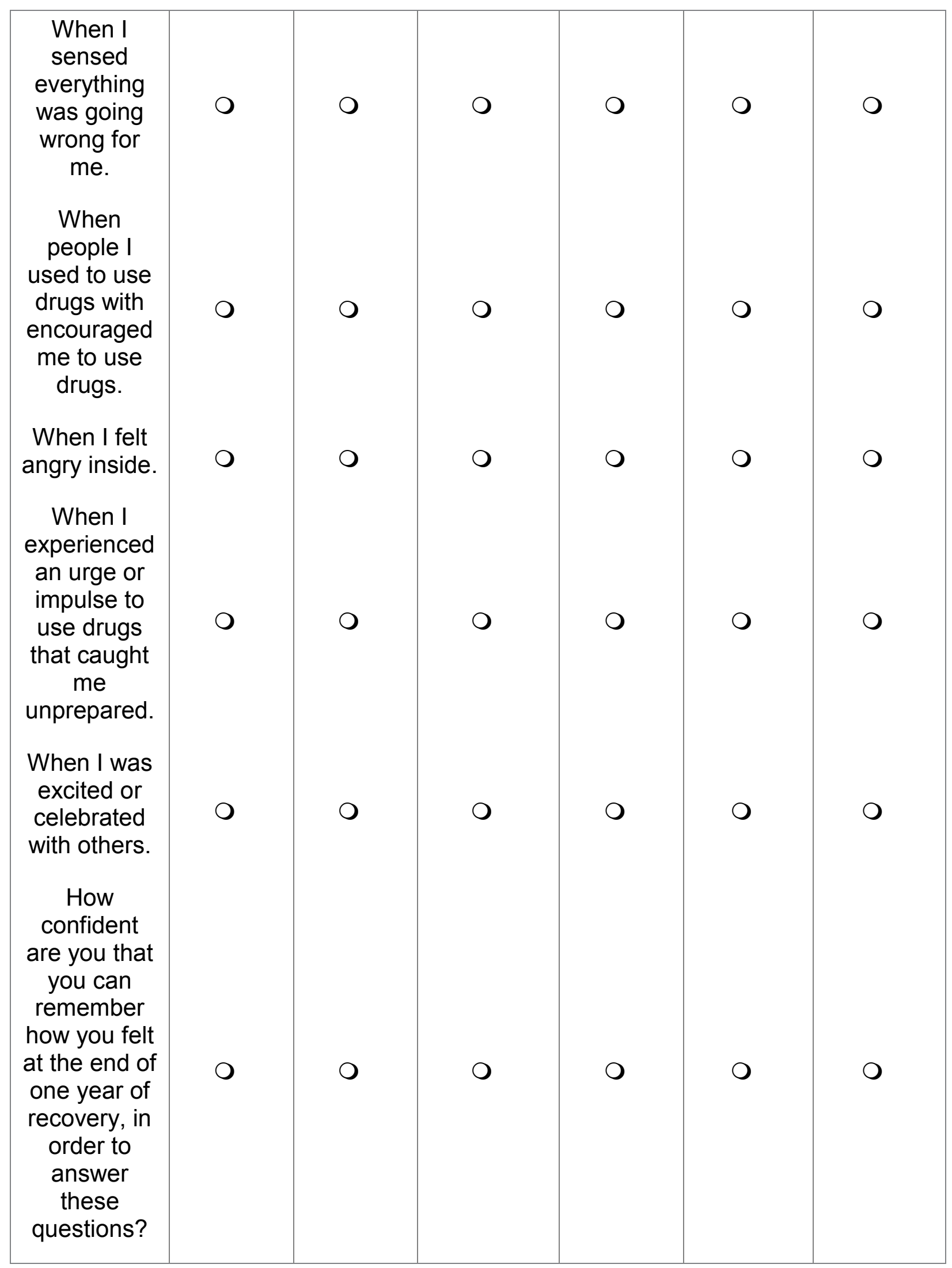


Q51 Do you identify as being in recovery from alcoholism?
O Yes
O No

Q52 Listed below are a number of situations that lead some people to use alcohol. Please think back to the end of your first year of recovery. We would like to know how confident you were that you would not use alcohol in each situation about one year after your recovery began.For each situation (items to the left), select the number that best describes the extent to which you were confident you would not use alcohol. If the situation is not applicable to you click on "Not applicable to me." $1=$ not at all 
confident $2=$ not very confident $3=$ moderately confident $4=$ very confident $5=$ extremely confident $6=$ not applicable to me 


\begin{tabular}{|c|c|c|c|c|c|c|}
\hline & $\begin{array}{l}\text { not at all } \\
\text { confident }\end{array}$ & $\begin{array}{l}\text { not very } \\
\text { confident }\end{array}$ & $\begin{array}{c}\text { moderately } \\
\text { confident }\end{array}$ & $\begin{array}{c}\text { very } \\
\text { confident }\end{array}$ & $\begin{array}{l}\text { extremely } \\
\text { confident }\end{array}$ & $\begin{array}{c}\text { not } \\
\text { applicable } \\
\text { to me }\end{array}$ \\
\hline $\begin{array}{l}\text { When I was } \\
\text { in agony } \\
\text { because of } \\
\text { stopping or } \\
\text { withdrawing } \\
\text { from } \\
\text { alcohol. }\end{array}$ & O & 0 & 0 & 0 & 0 & 0 \\
\hline $\begin{array}{l}\text { When I had } \\
\text { a headache. }\end{array}$ & 0 & 0 & 0 & 0 & 0 & 0 \\
\hline $\begin{array}{l}\text { When I was } \\
\text { feeling } \\
\text { depressed. }\end{array}$ & 0 & 0 & O & 0 & 0 & 0 \\
\hline $\begin{array}{c}\text { When I was } \\
\text { on vacation } \\
\text { and wanted } \\
\text { to relax. }\end{array}$ & O & 0 & 0 & 0 & 0 & 0 \\
\hline $\begin{array}{l}\text { When I was } \\
\text { concerned } \\
\text { about } \\
\text { someone. }\end{array}$ & 0 & 0 & O & 0 & 0 & 0 \\
\hline $\begin{array}{l}\text { When I was } \\
\text { worried. }\end{array}$ & 0 & 0 & O & O & 0 & O \\
\hline $\begin{array}{l}\text { When I had } \\
\text { the urge to } \\
\text { try just one } \\
\text { drink to see } \\
\text { what } \\
\text { happens. }\end{array}$ & 0 & 0 & 0 & 0 & 0 & 0 \\
\hline $\begin{array}{l}\text { When I was } \\
\text { offered a } \\
\text { drink in a } \\
\text { social } \\
\text { situation. }\end{array}$ & 0 & O & 0 & 0 & 0 & 0 \\
\hline
\end{tabular}




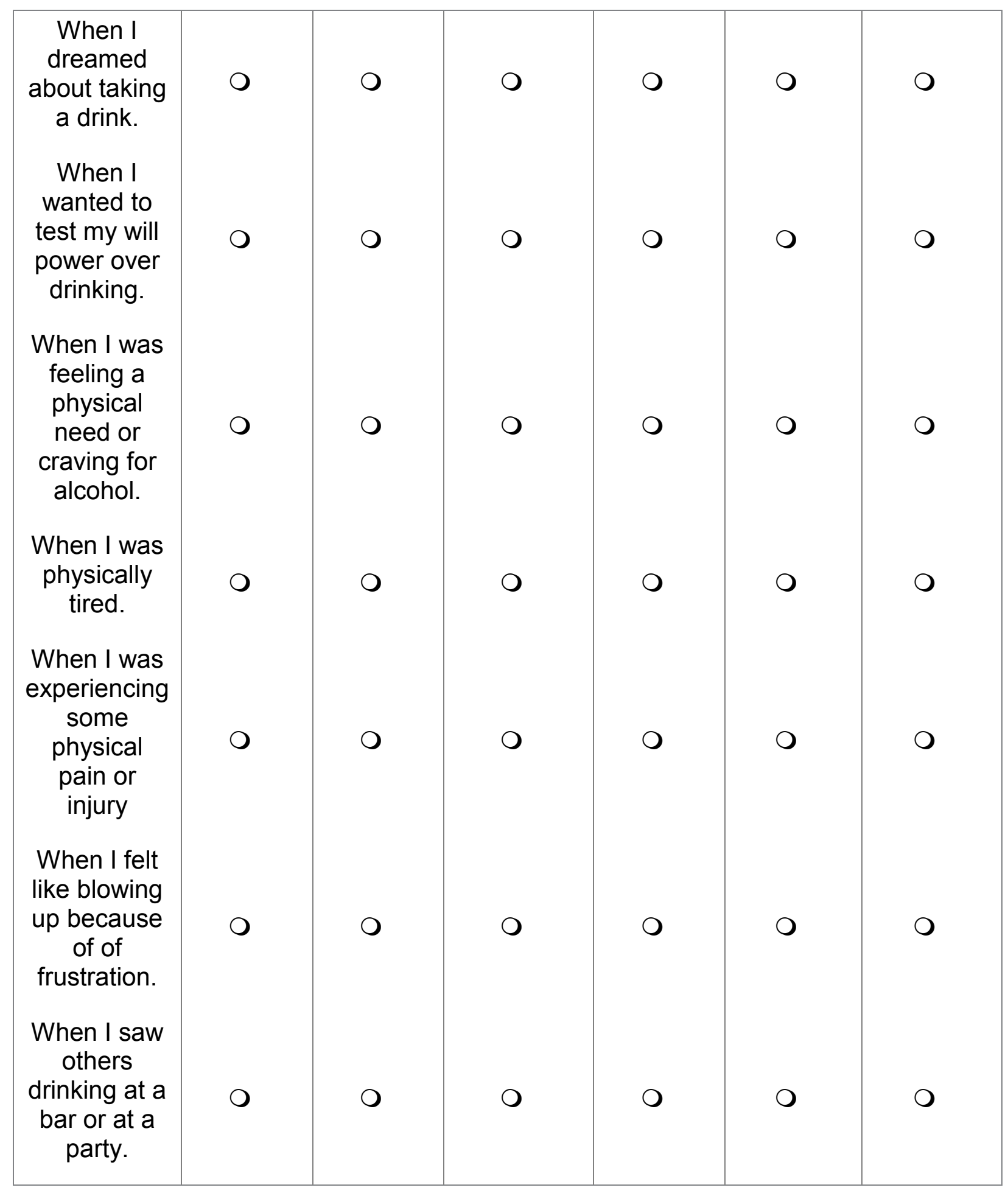




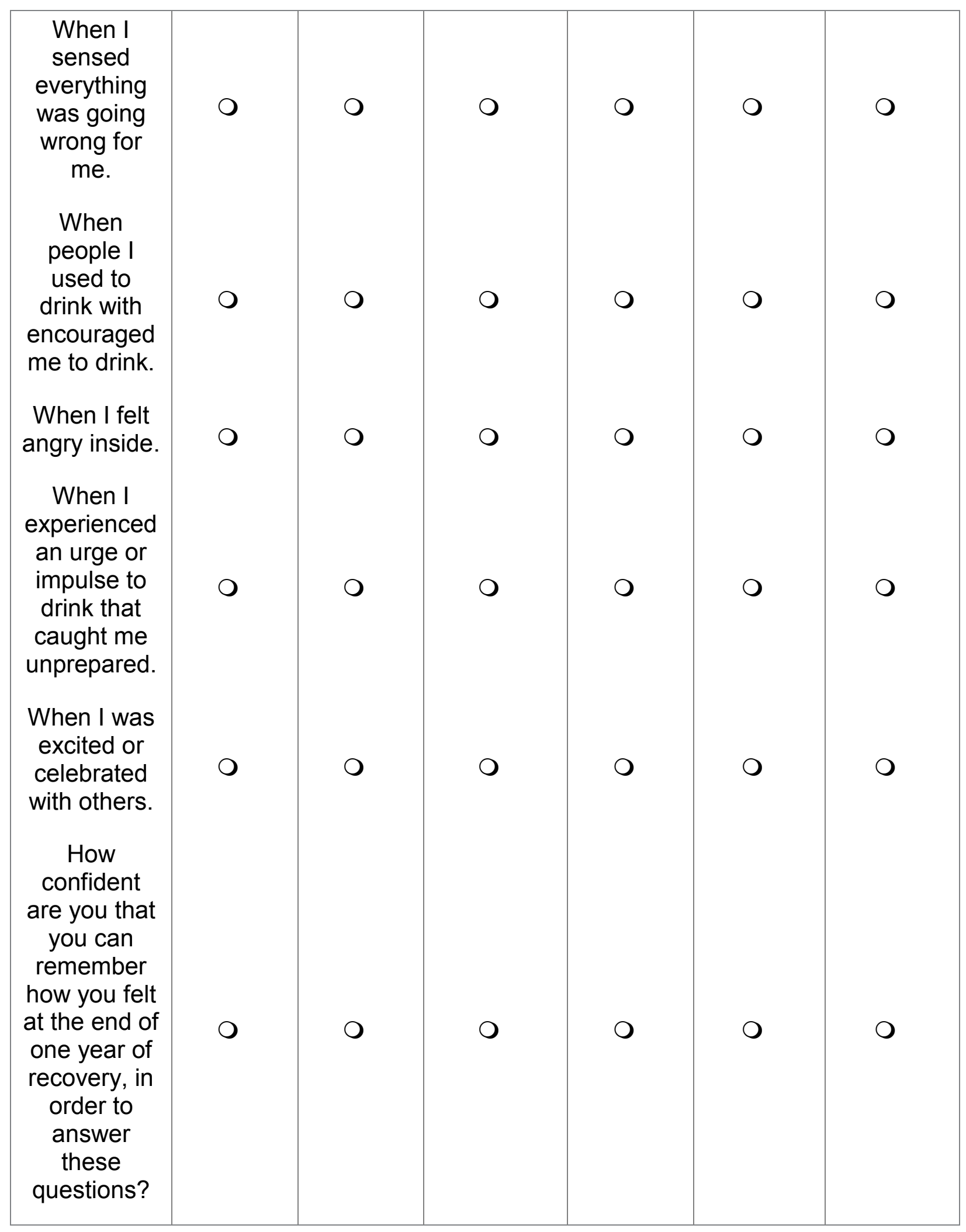


Q53 For this final question please consider the entire course of your current recovery, not just the first year.What most worked for you in your recovery?

Q54 Survey Completed. Thank you for your time! If you would like to receive a summary of the results, please send an email to me at william.gilbert@uconn.edu. If you would like to be included in the drawing for a Starbucks gift card please click on the link below. https://uconn.co1.qualtrics.com/SE/?SID=SV_5uUdZp4bCT4G981 